\title{
Levantamento fitossociológico comparativo entre sistema agroflorestal multiestrato e capoeiras como ferramenta para a execução da reserva legal
}

\author{
Luís Cláudio Maranhão Froufe ${ }^{1}$, Carlos Eduardo Sícoli Seoane ${ }^{1}$ \\ 'Embrapa Florestas, Estrada da Ribeira, Km 111, CP 319, CEP 83411-000, Colombo, PR, Brasil
}

"Autor correspondente:
luisao@cnpf.embrapa.br

Termos para indexação:

Código Florestal Brasileiro

Fitossociologia

Floresta Ombrófila Densa Atlântica

SAF

\section{Index terms:}

Brazilian Forest Code

Fitossociology

Atlantic Rain Forest

AF system

Histórico do artigo:

Recebido em 23 nov 2010

Aprovado em 26 ago 2011

Publicado em 30 set 2011

doi: 10.4336/2011.pfb.31.67.203
Resumo - A reserva legal (RL), normatizada pelo Novo Código Florestal, Lei 4.771/65, vem sendo alvo de críticas, desde sua criação, sobretudo sob a alegação de que interfere nos processos produtivos da propriedade rural e apresenta dificuldade na sua execução. Os sistemas agroflorestais (SAF) multiestrato são práticas de manejo conservacionista do solo já aceitos pela legislação brasileira como uma alternativa técnica para a execução da RL. Este trabalho teve por objetivo avaliar a composição florística e a fitossociologia de SAF e de capoeiras em diferentes estágios de sucessão, em propriedades rurais da região do Vale do Ribeira, no Estado de São Paulo. Os resultados demonstram que o SAF multiestrato comporta número e diversidade de espécies similares às capoeiras, atendendo aos pré-requisitos legais mínimos para utilização na recuperação e manejo da RL. Também foi observado o ressurgimento de diversas espécies nativas na regeneração natural, corroborando o potencial de utilização desses SAF nos processos de restauração de ecossistemas degradados. Apesar disso, estes sistemas agroflorestais carecem de melhorias em seu manejo silvicultural para propiciar a produção florestal pretendida pelos agricultores, bem como sua sustentabilidade.

\section{Fitossociological inventory in a multistrata agroforestry system as a} tool for legal reserve execution

\begin{abstract}
The legal reserve (RL) is by the Brazilian Forest Code a portion of the total area of a farm where the use of the natural resources is to be done on a sustainable basis aiming the ecological processes, and biodiversity conservation and the shelter and protection of native fauna and flora. The existence of RL has been criticized since its creation, specially by the allegation that it interferes on productive processes and for regarding the difficulties of its implantation. The multistrata agroforestry systems (AFS) are widely accepted as a conservative management practice, even in Brazilian legislation, and it is an alternative technique for the implantation of the RL. This work, carried altogether in small farms containing multistrata AFS and natural forests regeneration treatments (some of them already registered as RL) showed that this AFS, although productive systems, hold similar number and diversity of species to the renenerating forest, satisfying the legal minimum requisites expected in $\mathrm{RL}$ and thus suitable to be used as a technology for recovering and managing the RL. Moreover, as its management is agroecological, it was observed the recolonization of several native species, corroborating the potential use of these AFS in ecological restiration processes. Those agroforestry systems, however, need additional silvicultural practices to improve forestry production and sustainability.
\end{abstract}




\section{Introdução}

A cobertura vegetal nativa costuma ser vista como um empecilho à colonização e/ou ao desenvolvimento agrícola. A ocupação desordenada do território brasileiro promoveu o desmatamento em vários biomas, sobretudo da Mata Atlântica, cujos remanescentes representam $11,4 \%$ a $16 \%$ de sua área original, em sua maioria ( $>80 \%)$ distribuídos em fragmentos menores que 50 ha, com forte efeito de borda e muito distantes entre si (Ribeiro et al., 2009). Atualmente existem práticas que podem reverter esta realidade, ou minimizar seus efeitos negativos, aliando a produção de alimentos e a manutenção da capacidade produtiva em médio e longo prazo, tais como o plantio direto e o desenvolvimento de sistemas agroflorestais, além da elaboração de leis para preservar os recursos naturais, conservar a biodiversidade e proteger o solo contra processos de degradação.

A reserva legal (RL) foi normatizada pela Lei Federal 4.771, de 15/09/65, pelo Código Florestal (Brasil, 1965), posteriormente modificada pela Lei $\mathrm{n}^{0} 7.803$, de 18/07/89 e pela medida provisória (MP) $\mathrm{n}^{\circ} 1.956-50$, de 28/05/2000, reeditada até a MP n ${ }^{\circ} 2.166-67$, de 25/08/01 e vigente por força da Emenda Constitucional $n^{\circ} 32$, de 11/09/01 (Brasil, 2001). A RL se caracteriza como área localizada no interior de uma propriedade rural, excetuada a área de preservação permanente (APP), necessária ao uso sustentável dos recursos naturais, à conservação e reabilitação dos processos ecológicos, à conservação da biodiversidade e ao abrigo e proteção de fauna e flora nativas. Sua extensão deve ser de $80 \%$ na Amazônia Legal, 35\% no cerrado na Amazônia Legal e $20 \%$ nas demais regiões e/ou outras formas de vegetação. A Lei 8.171, de 17/01/91 (Brasil, 1991), que instituiu a Política Nacional de Agricultura, regulamenta que a obrigatoriedade de recomposição da RL nas propriedades e assentamentos rurais tenha um prazo final de execução em 2018.

Mas qual seria a área de RL a ser recuperada no Brasil? Somente no Estado do Paraná, essas estimativas podem variar de 610 mil a 2,2 milhões de hectares (Carpanezzi \& Carpanezzi, 2006; Sociedade de Pesquisa em Vida Selvagem, 2006; Leal, 2007). Do ponto de vista técnico, a execução da RL florestal exige o domínio da silvicultura comercial de espécies naturais, em suas várias formas, com a implantação e manejo de plantações mistas e o manejo de florestas naturais e reconstituídas.

Iniciativas como a criação de unidades de conservação são importantes para a proteção de áreas naturais, mas são insuficientes para conservar a biodiversidade florestal (Daily et al., 2001).

Os sistemas agroflorestais (SAF) multiestrato são práticas de manejo em que a presença do componente arbóreo, a diversidade de espécies e a grande produção de biomassa favorecem a sustentabilidade ambiental, sendo muito difundidos em várias regiões do mundo (Benjamin et al., 2001; Caja-Giron \& Sinclair, 2001; Staver et al., 2001; Angel-Pérez \& Mendoza B., 2004; Granados, 2005; Silveira, 2005; Suyanto et al., 2005; Isaac et al., 2007; Holguín et al., 2007). No Brasil, predominam na Amazônia Ocidental, no sul da Bahia e na região do Alto Vale do Ribeira (Lehmann et al., 2001; Santos et al., 2002; Schroth et al., 2002). Nesses sistemas, a composição de espécies busca maximizar a oferta de luz e de nutrientes, tanto na escala horizontal quanto na vertical (daí a sua classificação como multiestrato) e, em geral, tende a se assemelhar a ambientes em estágio de sucessão secundária (Götsch, 1997).

O uso de SAF para a recomposição de áreas de RL e/ou de APP começou a se tornar realidade com a publicação, no Estado do Paraná, da Portaria no 157, de 13/10/05, do Instituto Ambiental do Paraná (IAP), que normatiza a utilização permanente de espécies exóticas arbóreas para a recuperação de áreas de RL em sistemas agroflorestais multiestrato, com um mínimo de cinco espécies arbóreas nativas e 200 covas por hectare (Paraná, 2005). Posteriormente, no Estado de São Paulo, o Decreto $\mathrm{n}^{\circ}$ 50.889, de 16/06/06 (São Paulo, 2006), permitiu o plantio, em caráter temporário, de espécies exóticas como pioneiras em sistemas agrossilvipastoris na recomposição da RL, desde que o projeto fosse aprovado pelo órgão responsável e que não representasse riscos à vegetação existente ou aos processos de recuperação ou regeneração. Mais recentemente, a Secretaria Estadual do Meio Ambiente (Sema) do Paraná editou a Resolução ${ }^{\circ} 13$, de 24/03/10 (Paraná, 2010), que estendeu a possibilidade de computar espécies germinadas entre as cinco mínimas previstas na portaria IAP $n^{\circ} 157 / 05$.

No âmbito federal, a Instrução Normativa $\mathrm{n}^{\circ} 5$, de 8/09/09, do Ministério do Meio Ambiente (MMA), admitiu o uso desses sistemas multiestrato para a recuperação da RL, em todo o território nacional, e ampliou o seu uso para a recuperação de APP, desde que sejam observados critérios técnicos, tais como o não plantio de espécies exóticas. Apesar dessas concessões, há poucas pesquisas quanto ao uso de SAF para a recuperação da RL (Beltrame et al., 2006), nenhuma enfocando o uso de SAF multiestrato. Desta 
forma, para a $\mathrm{RL}$ de pequenas propriedades rurais, os sistemas agroflorestais (SAF) e, particularmente, os SAF multiestrato (SAF-ME), apresentam-se como uma proposta harmonizadora entre os interesses de produção e de conservação ambiental (Brasil, 2009).

Levantamentos florísticos e fitossociológicos fornecem informações importantes para a compreensão dos padrões biogeográficos de diversas formações vegetais (OliveiraFilho, 1989; Canalez et al., 2006), podendo subsidiar a determinação de áreas prioritárias para a conservação e manejo (Cardoso-Leite et al., 2004).

O objetivo deste trabalho foi estudar a composição florística e os parâmetros fitossociológicos de SAF e capoeiras, de modo a identificar o potencial de utilização dos SAF multiestrato como ferramenta para a execução da Reserva Legal em pequenas propriedades rurais na região do Alto Vale do Ribeira.

\section{Material e métodos}

O presente trabalho foi desenvolvido na região do Alto Vale do Ribeira, no município de Barra do Turvo, SP, no período entre julho de 2007 a março de 2008. Esta região, de relevo bastante acidentado e altitudes variando até $1.000 \mathrm{~m}$, se insere em um remanescente da Floresta Ombrófila Densa Atlântica (Veloso \& Góes-Filho, 1982). Seu clima é definido como Subtropical Úmido Mesotérmico ( $\mathrm{Cfb}$ nas porções mais elevadas do território, e Cfa nas porções mais baixas), com estação quente e úmida de setembro a março, precipitação média anual variando de $1.500 \mathrm{~mm}$ a $2.000 \mathrm{~mm}$, e temperatura média anual de $21,5{ }^{\circ} \mathrm{C}$ (Rousselet-Gadenne, 2004). Dentre os solos da região, destacam-se os neossolos, argissolos, cambissolos e afloramentos rochosos (Sociedade de Pesquisa em Vida Selvagem, 1996; Santos et al., 2006).

O levantamento do componente arbóreo e das mudas germminadas foi realizado em diferentes sistemas de uso da terra (SUT): SAF agroecológicos (SAF multiestrato), agricultura convencional, pastagem, e em áreas de capoeira, em diversas propriedades rurais, sendo selecionados três produtores para cada sistema de uso da terra (Tabela 1).

A escolha das propriedades deu-se por indicação dos parceiros locais e pelo contato pessoal com cada um dos produtores indicados. Os produtores agroecológicos foram indicados pela Associação dos Produtores Agroecológicos de Barra do Turvo e Adrianópolis (Cooperafloresta), e os convencionais foram indicados pela Coordenadoria de Assistência Técnica Integral (Cati).

A quantidade de famílias associadas à Cooperafloresta tem variado bastante ao longo de sua existência, em função, principalmente, de questões relacionadas à comercialização dos produtos e a fatores externos, tais como a regularização fundiária das propriedades. De um universo de 82 famílias, distribuídas em diversos núcleos comunitários (Areia Branca, Cedro e Ribeirão Grande, Terra Seca, Indaiatuba, Salto Grande, Córrego do Franco e Três canais, e BR116) é grande a variação de formas particulares de manejo agroflorestal (segundo preceitos próprios de cada produtor), idades de plantio e condições edáficas desses plantios. No intuito de padronizar essas variáveis, foram indicados três produtores, em cada uma das comunidades Córrego do Franco e Três Canais, Salto Grande e Terra Seca.

Tabela 1. Propriedades rurais de Barra do Turvo, SP, atividades rurais desenvolvidas e seus sistemas de uso da terra.

\begin{tabular}{|c|c|c|c|}
\hline SUT & Descrição geral & Sigla & Triplicatas \\
\hline \multirow{3}{*}{$\mathrm{AC}$} & \multirow{3}{*}{$\begin{array}{l}\text { Agricultura convencional, com a aplicação } \\
\text { de fertilizantes }\end{array}$} & $\mathrm{AB}$ & Plantio de abóbora \\
\hline & & MA & Plantio de maracujá \\
\hline & & PU & Plantio de pupunha \\
\hline \multirow{3}{*}{$\mathrm{AF}$} & \multirow{3}{*}{$\begin{array}{l}\text { Sistemas agroflorestais multiestrata } \\
\text { produtivos, com diferentes idades (produção } \\
\text { bananeira) }\end{array}$} & SAF 4 & SAF-ME com 4 anos \\
\hline & & SAF 8 & SAF-ME com 8 anos \\
\hline & & SAF 16 & SAF-ME com 16 anos \\
\hline \multirow{3}{*}{ PT } & \multirow{3}{*}{$\begin{array}{l}\text { Sistema pastoril, com criação de bubalinos } \\
\text { (produção de leite) }\end{array}$} & PPD & Pastagem pouco degradada \\
\hline & & PMD & Pastagem medianamente degradada \\
\hline & & PDE & Pastagem muito degradada \\
\hline \multirow{3}{*}{$\mathrm{CP}$} & \multirow{3}{*}{ Capoeira } & $\mathrm{C} 5$ & Capoeiras com 5 anos de pousio \\
\hline & & $\mathrm{C} 20$ & 20 anos de pousio \\
\hline & & $\mathrm{C} 30$ & $>30$ anos de pousio \\
\hline
\end{tabular}

SAF 4 (predominando bananais); SAF 8 (múltiplo - banana, abacaxi, pupunha e olerícolas); SAF 16 (predominando bananais); C5 e C20 (averbadas como reserva legal). 
Já para os agricultores convencionais foram indicados três produtores da atividade pecuária (gado leiteiro bubalino) e outros três de culturas agrícolas (culturas diversas, com diferentes graus de aplicação de insumos). Além disso, foram avaliadas outras três áreas de capoeira, com diferentes idades de regeneração natural, sendo duas delas já averbadas como Reserva Legal.

Em cada um dos sistemas de uso da terra (agricultura convencional - AC; Agrofloresta - AF; capoeira, CP; e pastagem - PT) foram demarcadas nove parcelas de $25 \mathrm{~m} \times 10 \mathrm{~m}$, nas quais foi realizado o levantamento fitossociológico. Foram amostrados todos os indivíduos com circunferência à altura do peito (CAP) a 1,30 m do solo, igual ou superior a $15 \mathrm{~cm}$, dos quais foram anotados, além dos valores de CAP (com fita métrica), a altura total (com hipsômetro), o nome comum, o nome científico e a família. Nas parcelas contendo pupunha, foi realizada a medição do diâmetro à altura do peito (DAP) por meio de uma suta, em medidas ortogonais, pois todos os indivíduos eram com espinho. Para as análises fitossociológicas, os dados foram convertidos para DAP.

O levantamento das mudas germinadas (notação adotada em Brasil, 2009, artigo 9º, inciso VIII) foi realizado em três subparcelas de $1 \mathrm{~m}^{2}$, dispostas aleatoriamente no interior das parcelas do levantamento arbóreo, das quais foram coletados todos os indivíduos com até $1 \mathrm{~m}$ de altura do solo. Demais formas de vegetação (lianas, epífitas, briófitas, etc.) não foram levantadas pela exiguidade do tempo de avaliação, pela natureza preliminar do trabalho e pelo caráter legal dos objetivos, já que a referida legislação refere-se tão somente às espécies florestais arbóreas perenes e à sua regeneração natural. De todo material vegetativo e reprodutivo coletado, tanto das mudas germinadas quanto dos indivíduos cujo DAP fora mensurado, foram feitas exsicatas que foram depositadas no herbário do laboratório de ecologia da Embrapa Florestas. A identificação botânica dos indivíduos mensurados foi realizada após consulta em bibliografia específica, pela comparação do material coletado com exsicatas do próprio Herbário e com o auxílio de especialistas.

O cálculo dos descritores fitossociológicos foi realizado mediante a utilização do programa Fitopac (Shepherd, 1995), em que foram determinados: o número de indivíduos $(\mathrm{N})$, as densidades (D), as densidades relativas (DR), as frequências (F), as frequências relativas (FR), as dominâncias (Do), as dominâncias relativas (DoR) e os valores de importância, organizados em um índice (IVI).

Do ponto de vista de outros descritores, foram determinados também o índice de diversidade de Shannon (H') (Shannon \& Weaver, 1949), o índice de dominância de Simpson (D) e o índice de similaridade de Jaccard (Sj) (Pielou, 1975).

\section{Resultados e discussão}

\section{Distribuição das famílias e espécies nos diferentes sistemas de uso do solo}

Nas áreas de SAF, as famílias mais ricas em espécies foram: Fabaceae (7 espécies); Lauraceae e Myrtaceae (4); Arecaceae, Euphorbiaceae e Sapindaceae (3); e Verbenaceae (2).

Nas áreas ocupadas com o SAF multiestrato foi observada a ocorrência de 4.240 indivíduos ha-1 de 46 espécies e 24 famílias (Tabela 2). A espécie com maior número de indivíduos (2.080 ind. ha ${ }^{-1}$ ) foi a bananeira (Musa paradisiaca), de diversas variedades (ouro, caturra, caturra-Maranhão, limão, maçã, missouri, pacová, rabo-de-mono, são tomé, veiaca, zinca e pão), em função de ser a principal cultura comercializada pelos produtores agroflorestais locais. Destacamos, também, a ocorrência de 507 ind. ha ${ }^{-1}$ de juçara (Euterpe edulis), sendo 1.080 ind. ha ${ }^{-1}$ no SAF 8, e 440 ind. ha $^{-1}$ no SAF 16, principalmente quando comparados à quantidade de indivíduos dessa espécie nas áreas de capoeira (40 e 760 ind. ha ${ }^{-1}$, respectivamente, em C5 e C30. Esta espécie figura na Lista oficial de espécies da flora brasileira ameaçadas de extinção (BiodiversitasInternational Union for Conservation of Nature, 2005) e vem sendo largamente cultivada nesses SAF para fins alimentares (frutos). Assim, ao mesmo tempo em que esses agricultores agroecológicos introduzem novos indivíduos de juçara à paisagem rural, a mudança no modelo de utilização alimentar permite aumentar a longevidade dos indivíduos de juçara, propicia seus eventos de frutificação, a atração da avifauna local e disponibiliza sementes que são utilizadas para a produção de mudas da espécie (para replantios no SAF e nas capoeiras adjacentes) (Tabelas 3 e 4). 
Tabela 2. Famílias, espécies e número de indivíduos por hectare com DAP $\geq 5 \mathrm{~cm}$ dos diferentes sistemas de uso da terra (agricultura convencional, agrofloresta, capoeira e pastagem), em Barra do Turvo, SP.

\begin{tabular}{|c|c|c|c|c|c|c|c|c|c|c|}
\hline \multirow{3}{*}{ Família } & \multirow{3}{*}{ Espécie } & \multirow{3}{*}{ GE } & \multicolumn{8}{|c|}{ Sistema de uso da terra (SUT) } \\
\hline & & & \multicolumn{2}{|l|}{$\mathbf{A C}$} & \multicolumn{2}{|c|}{ SAF } & \multicolumn{3}{|c|}{$\mathbf{C P}$} & \multirow{2}{*}{$\begin{array}{r}\text { PT } \\
\text { PPD }\end{array}$} \\
\hline & & & PU & SAF4 & SAF8 & SAF16 & C5 & $\mathrm{C20}$ & $\mathbf{C 3 0}$ & \\
\hline Anacardiaceae & Spondias cytherea Sonn. Tuss & $\mathrm{CL}$ & & 40 & & & & & & \\
\hline \multirow{3}{*}{ Annonaceae } & Annona crassifolia Mart. & ST & & & & & & 80 & & \\
\hline & Rollinia mucosa (Jacquin) Baill. & nd & & & 40 & & & & & \\
\hline & Rollinia sericea (R. E. Fries) R. E. Fries & ST & & & & & & 80 & 120 & \\
\hline Araliaceae & Didmopanax morototonii (Aubl.) Dene. et Planch. & SI & & & & & 40 & & & \\
\hline \multirow{4}{*}{ Arecaceae } & Bactris gasipaes Kunth & EX & 3.560 & & 40 & 40 & & & & \\
\hline & Euterpe edulis Mart. & $\mathrm{CL}$ & & & 1.080 & 440 & 40 & & 950 & \\
\hline & Roystonea oleracea (N. J. Jacq.) O. F. Cook & EX & & & & 40 & & & & \\
\hline & Syagrus romanzoffiana (Cham.) Glass. & SI & & & & & 40 & 40 & & \\
\hline Asteraceae & Baccharis sp. & $\mathrm{P}$ & & 40 & & & 40 & & & \\
\hline Bombacaceae & Pachira aquatica Aubl. & EX & & & & 40 & & & & \\
\hline Caricaceae & Carica papaya $\mathrm{L}$. & EX & & 120 & & & & & & \\
\hline Cecropiaceae & Cecropia galziovii Snethlage & $\mathrm{P}$ & & & & 360 & 80 & & 40 & \\
\hline \multirow{4}{*}{ Euphorbiaceae } & Alchornea triplinervia (Spreng.) M. Arg. & SI & & & 40 & 40 & & 40 & 160 & \\
\hline & Croton floribundus Spreng. & $\mathrm{P}$ & & 40 & & & 1.360 & & & \\
\hline & Ricinus communis $\mathrm{L}$. & EX & & 40 & & & & & & \\
\hline & Sapium glandulatum (Vell.) Pax & $\mathrm{P}$ & & & & & 40 & & & \\
\hline \multirow{11}{*}{ Fabaceae } & Anadenanthera peregrina (L.) Speg. & SI & & & & & & & 40 & \\
\hline & Andira legalis (Vell.) Toledo & SI & & & & & 160 & & & \\
\hline & Bauhinia forficata Link & $\mathrm{P}$ & & 80 & & & & 200 & & \\
\hline & Inga edulis Mart. & SI & & & & & & & 40 & \\
\hline & Inga marginata Willd. & $\mathrm{CL}$ & & & & 40 & 80 & 80 & & \\
\hline & Lonchocarpus muehlbergianus Hassl. & SI & & & & & & 40 & & \\
\hline & Lonchocarpus sp. & SI & & 40 & 120 & & 80 & 240 & & \\
\hline & Machaerium nyctitans (Vell.) Benth & $\mathrm{P}$ & & & 140 & & 240 & 200 & & \\
\hline & Machaerium stipitatum (DC.) Vog. & SI & & 160 & & 40 & & 160 & & \\
\hline & Mimosa bimucronata (DC.) O. Kuntze & $\mathrm{P}$ & & & & 40 & & & & \\
\hline & Senna multijuga (Rich.) Irwin et Barn. & SI & & & 40 & 40 & 360 & 320 & & \\
\hline \multirow{2}{*}{ Flacourtiaceae } & Casearia decandra Jacq. & SI & & & & & 40 & & 40 & \\
\hline & Casearia sylvestris $\mathrm{Sw}$. & SI & & & & & 360 & 280 & 360 & \\
\hline \multirow{4}{*}{ Lauraceae } & Nectandra grandiflora Nees & ST & & & & 40 & 40 & 40 & & \\
\hline & Nectandra lanceolata Nees et Mart. ex Nees & $\mathrm{ST}$ & & & 40 & 120 & 160 & 160 & 80 & \\
\hline & Nectandra megapotamica (Spreng.) Mez & SI & & & & & & & 40 & \\
\hline & Nectandra membranaceae (Spreng.) Mez & $\mathrm{P}$ & & & & & & & 40 & \\
\hline \multirow{2}{*}{ Lauraceae } & Ocotea puberula (Reich.) Nees & SI & & & & 80 & & & 40 & \\
\hline & Persea americana & EX & & & 40 & & & & & \\
\hline Melastomataceae & Tibouchina mutabilis Cong. & $\mathrm{P}$ & & & & 120 & & & & \\
\hline Meliaceae & Guarea kunthiana A. Juss. & SI & & & & & & & 320 & \\
\hline Miristicaceae & Virola oleifera (Schott) A. C. Smith & $\mathrm{P}$ & & & 40 & & & & 40 & \\
\hline
\end{tabular}


Tabela 2. Continuação.

\begin{tabular}{|c|c|c|c|c|c|c|c|c|c|c|}
\hline \multirow{3}{*}{ Família } & \multirow{3}{*}{ Espécie } & \multirow{3}{*}{ GE } & \multicolumn{8}{|c|}{ Sistema de uso da terra (SUT) } \\
\hline & & & \multicolumn{2}{|l|}{$\mathbf{A C}$} & \multicolumn{2}{|c|}{ SAF } & \multicolumn{3}{|c|}{$\mathbf{C P}$} & \multirow{2}{*}{$\frac{\text { PT }}{\text { PPD }}$} \\
\hline & & & PU & SAF4 & SAF8 & SAF16 & C5 & $\mathrm{C20}$ & $\mathbf{C 3 0}$ & \\
\hline \multirow{3}{*}{ Moraceae } & Artocarpus heterophyllus Lam. & EX & & & 80 & 200 & 40 & & & \\
\hline & Ficus sp. & $P$ & & & & & & & 40 & \\
\hline & $\begin{array}{l}\text { Sorocea bonplandii (Baill.) Burger, Lanjow \& } \\
\text { Boer }\end{array}$ & SI & & & & & & & 200 & \\
\hline Musaceae & Musa paradisiaca & EX & & 2.240 & 2.560 & 1.440 & & & & \\
\hline Myrsinaceae & Rapanea umbellata (Mart. ex DC.) Mez & SI & & & & 240 & 120 & 80 & & \\
\hline \multirow{6}{*}{ Myrtaceae } & Campomanesia neriiflora (O. Berg.) Nied. & ST & & & & & & 80 & & \\
\hline & Eugenia uniflora $\mathrm{L}$. & ST & & & 40 & & & & & \\
\hline & Myrcia crassifolia (Miq.) Kiaersk. & SI & & & & 80 & & 160 & & \\
\hline & Myrciaria cauliflora (Mart.) O. Berg. & ST & & & & 80 & & & & \\
\hline & Psidium guajava $\mathrm{L}$. & EX & & 40 & 120 & 160 & & & & 40 \\
\hline & Psidium sp. & CL & & & & & 280 & 800 & & \\
\hline Phytolaccaceae & Phytolacca dioica $\mathrm{L}$. & $\mathrm{P}$ & & & & 40 & & & & \\
\hline Piperaceae & Piper aduncum L. & ST & & & 80 & 360 & 40 & 80 & & \\
\hline Rhamnaceae & Hovenia dulcis Thunberg & EX & & 40 & & 40 & & & & \\
\hline Rosaceae & Prunus persica & EX & & & & 40 & & & & \\
\hline \multirow{2}{*}{ Rubiaceae } & Rudgea jasminioides (Cham.) Müll. Arg. & SI & & & & & & & 80 & \\
\hline & Bathysa meridionalis Smith \& Downs & SI & & & & & & & 760 & \\
\hline \multirow{4}{*}{ Rutaceae } & Citrus reticulata Blanco & EX & & & & 40 & & & & \\
\hline & Citrus x limon L. & EX & & & 40 & 40 & & & & \\
\hline & Citrus sp. & EX & & & & 40 & & & 40 & \\
\hline & Zanthoxyllum riedelianum Engl. & $\mathrm{P}$ & & & & & 40 & & & \\
\hline \multirow{3}{*}{ Sapindaceae } & Allophylus edulis (St. Hill.) Radlk. & $P$ & & & 40 & & & & & \\
\hline & Cupania vernalis Camb. & SI & & & 40 & & & & & \\
\hline & Matayba elaegnoides Radlk. & SI & & & & 40 & & 80 & 240 & \\
\hline Solanaceae & Solanum granuloso-leprosum Dun. & ST & & & & 40 & & & & \\
\hline Tiliaceae & Luehea divaricata Mart. & $P$ & & & & & 120 & 80 & & \\
\hline Ulmaceae & Trema micrantha (L.) Blum. & $P$ & & 480 & 40 & & & & & \\
\hline \multirow{3}{*}{ Verbenaceae } & Aegiphila sellowiana Cham. & $\mathrm{P}$ & & & & & 40 & & & \\
\hline & Cytharexyllum myrianthum Cham. & $P$ & & 40 & 40 & 80 & 160 & 40 & 40 & \\
\hline & Vitex sp. & SI & & & & 80 & & & & \\
\hline
\end{tabular}

GE - Grupo ecológico (P - Pioneira, SI - Secundária inicial, ST - Secundária tardia, CL - clímax, EX- exótica strito sensu, nd- não determinado na bibliografia consultada); PU - plantio de pupunha; SAF 4 (jovem - 4 anos); SAF 8 (intermediário - 8 anos); SAF 16 (maduro - 16 anos); C5 (capoeira de 5 anos averbada como RL); C20 (capoeira de 20 anos averbada como RL); C30 (capoeira com mais de 30 anos); PPD (pastagem pouco degradada). 
Tabela 3. Espécies utilizadas nos SAF multiestrata dos produtores agroflorestais avaliados em Barra do Turvo, SP, segundo suas finalidades (quantidade total plantada).

\begin{tabular}{|c|c|c|c|c|c|}
\hline \multirow{2}{*}{ Nome comum } & \multirow{2}{*}{ Nome científico } & \multirow{2}{*}{ Família } & \multicolumn{3}{|c|}{ Quantidade (por proprietário) } \\
\hline & & & SAF 4 & SAF 8 & SAF 16 \\
\hline \multicolumn{6}{|c|}{ Madeireiras } \\
\hline Angico & Anadenanthera peregrina & Fabaceae & 100 & 800 & 40 \\
\hline Araucária & Araucaria angustifolia & Araucariaceae & & 200 & 300 \\
\hline Araribá & Centrolobium tomentosum & Fabaceae & 10 & 100 & 80 \\
\hline Cabreúva & Myrocarpus frondosus & Fabaceae & & 20 & 50 \\
\hline Cajarana & Cabralea canjerana & Meliaceae & 5 & 100 & 40 \\
\hline Canafistula & Cassia fistula & Fabaceae & & & 30 \\
\hline Canela & Nectandra sp. & Lauraceae & 30 & 810 & 10 \\
\hline Caviúna & Dalbergia nigra & Fabaceae & & & 20 \\
\hline Cedro & Cedrela fissilis & Meliaceae & & 100 & 150 \\
\hline Copaíba & Copaifera langsdorfii & Fabaceae & & 300 & 8 \\
\hline Erva-mate & Ilex paraguariensis & Aquifoliaceae & 6 & 6 & \\
\hline Flamboaiã & Delonix regia & Fabaceae & & & 10 \\
\hline Ipê & Tabebuia sp. & Bignoniaceae & 50 & 100 & 120 \\
\hline Jatobá & Hymenaea courbaril & Fabaceae & 5 & 50 & 50 \\
\hline Mogno & Swietenia macrophylla & Meliaceae & 300 & & 100 \\
\hline Pau-brasil & Caesalpinia echinata & Fabaceae & & & 5 \\
\hline Pau-ferro & Caesalpinia leyostacha & Fabaceae & & & 20 \\
\hline Peroba & Aspidosperma polyneuron & Apocynaceae & & & 50 \\
\hline Tarumã & Vitex sp. & Verbenaceae & 20 & 75 & 60 \\
\hline Assapeixe & Vernonia polyanthes & Asteraceae & 300 & 600 & \\
\hline Caroba (capeba) & Jacaranda sp. & Bignoniaceae & & 300 & \\
\hline Crandiúva & Trema micrantha & Ulmaceae & 100 & 20.000 & 300 \\
\hline Gliricídia & Gliricidia sepium & Fabaceae & 50 & 60 & \\
\hline Jaborandi & Piper aduncum & Piperaceae & 1.000 & 1.500 & \\
\hline Araticum & Rollinia sericea & Annonaceae & & 200 & 50 \\
\hline Aroeira & Astronium fraxinifolium & Anacardiaceae & & 50 & \\
\hline Capororoca & Campomanesia neriiflora & Myrtaceae & 50 & 20.000 & 200 \\
\hline Espinheira-santa & Maytenus ilicifolia & Celastraceae & 5 & & 100 \\
\hline Eucalipto & Eucalyptus sp. & Myrtaceae & & & 200 \\
\hline Figueira & Ficus sp. & Moraceae & & 9 & 30 \\
\hline Fumeiro-brabo & Solanum granuloso-leprosum & Solanaceae & 200 & 400 & \\
\hline Gabiroba & Campomanesia corymbosa & Myrtaceae & & 10 & \\
\hline Guanandi & Calophyllum brasiliensis & Clusiaceae & & & 10.000 \\
\hline Guapuruvu & Schizolobium parahyba & Fabaceae & 20 & 500 & 120 \\
\hline Imbaúba & Cecropia glaziovii & Cecropiaceae & 300 & 1.500 & 80 \\
\hline Ingá & Inga sp. & Fabaceae & 50 & 1.750 & 1.000 \\
\hline Ingá-de-metro & Inga marginata & Fabaceae & & 2 & \\
\hline Jacarandá & Machaerium nyctitans & Fabaceae & & 500 & \\
\hline Jacatirão & Tibouchina sp. & Melastomataceae & & 100 & 30 \\
\hline Jaracatiá & Jaracatia dodecaphylla & Caricaceae & & 50 & 3 \\
\hline
\end{tabular}


Tabela 3. Continuação.

\begin{tabular}{|c|c|c|c|c|c|}
\hline \multirow{2}{*}{ Nome comum } & \multirow{2}{*}{ Nome científico } & \multirow{2}{*}{ Família } & \multicolumn{3}{|c|}{ Quantidade (por proprietário) } \\
\hline & & & SAF 4 & SAF 8 & SAF 16 \\
\hline Leucena & Leucaena leucocephala & Fabaceae & 10.000 & 500 & 50 \\
\hline Mamica-de-cadela & Zanthoxyllum riedelianum & Rutaceae & 50 & 30 & 100 \\
\hline Miguel-pintado & Matayba elaegnoides & Sapindaceae & & 200 & 120 \\
\hline Paineira & Chorisia speciosa & Bombacaceae & & & 50 \\
\hline Pata-de-vaca & Bauhinia forficata & Fabaceae & & 300 & 100 \\
\hline Pau-d'alho & Gallesia integrifolia & Phytolaccaceae & & 50 & 6 \\
\hline Pau-sangue & Croton floribundus & Euphorbiaceae & 50 & & \\
\hline Saboeiro & Sapindus saponaria & Sapindaceae & & & 50 \\
\hline Sanção-do-campo & Mimosa caesalpiniifolia & Fabaceae & & & 60 \\
\hline Sombreiro & Clitorea racemosa & Fabaceae & & & 46 \\
\hline Taca (teca) & Tectona grandis & Lamiaceae & & 50 & \\
\hline Tapiá & Alchornea triplinervia & Euphorbiaceae & & 800 & \\
\hline Tupixava & Baccharis sp. & Asteraceae & & 200 & 50 \\
\hline Uva-do-japão & Hovenia dulcis & Rhamnaceae & & 500 & 15 \\
\hline \multicolumn{6}{|c|}{ Frutíferas } \\
\hline Abacaxi & Ananas comosus & Bromeliaceae & & & 3.000 \\
\hline Abiu & Lucuma caimito & Sapotaceae & & & 10 \\
\hline Acerola & Malpighia glabra & Malpighiaceae & 15 & 10 & 10 \\
\hline Ameixa & Prunus sp. & Rosaceae & 1.000 & 500 & 10 \\
\hline Amora & Rubus sp. & Rosaceae & & 500 & \\
\hline Araçá & Psidium sp. & Myrtaceae & 50 & 100 & 10 \\
\hline Bacupari & Garcinia gardneriana & Clusiaceae & & 20 & 30 \\
\hline Cabeludinha & Plinia glomerata & Myrtaceae & & 300 & \\
\hline Cacau & Theobroma cacao & Sterculiaceae & & 200 & 10 \\
\hline Cajá & Spondias sp. & Anacardiaceae & 20 & 102 & 28 \\
\hline Caju & Anacardium occidentalis & Anacardiaceae & 5 & 15 & 8 \\
\hline Caqui & Diospyros kaki & Ebenaceae & & 10 & 30 \\
\hline Carambola & Averrhoa carambola & Oxalidaceae & & 15 & \\
\hline Cereja & Prunus sp. & Rosaceae & & & 10 \\
\hline Figo & Ficus carica & Moraceae & & 10 & \\
\hline Fruta-do-conde & Annona coriacea & Annonaceae & 100 & 700 & 15 \\
\hline Goiaba & Psidium guajava & Myrtaceae & 80 & 2.000 & 100 \\
\hline Gramixama & Eugenia basiliensis & Myrtaceae & 10 & 6 & 8 \\
\hline Graviola & Annona muricata & Annonaceae & 500 & 300 & \\
\hline Jaboticaba & Myrciaria cauliflora & Myrtaceae & 30 & 400 & 100 \\
\hline Jambo & Sygygium sp. & Myrtaceae & & 200 & 15 \\
\hline Jambolão & Sygygium sp. & Myrtaceae & 10 & 15 & \\
\hline Jenipapo & Genipa americana & Rubiaceae & & 1 & 8 \\
\hline Lichia & Litchi chinensis & Sapindaceae & & 5 & \\
\hline Macadâmia & Macadamia sp. & Proteaceae & & & 5 \\
\hline Mamão & Carica papaya & Caricaceae & 50 & 10 & \\
\hline Manga & Mangifera indica & Anacardiaceae & 50 & 30 & 15 \\
\hline
\end{tabular}


Tabela 3. Continuação.

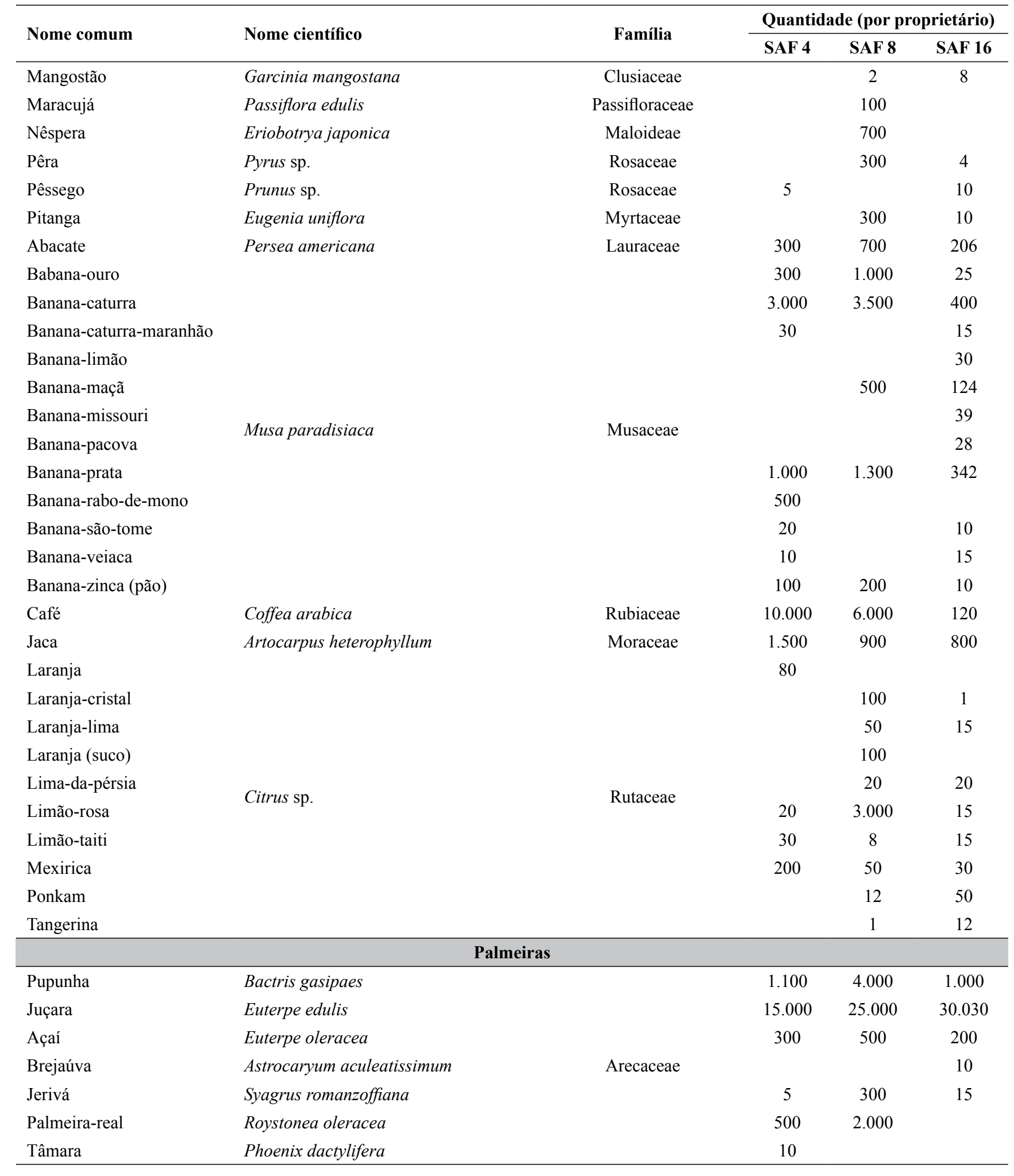


Tabela 3. Continuação.

\begin{tabular}{|c|c|c|c|c|c|}
\hline \multirow{2}{*}{ Nome comum } & \multirow{2}{*}{ Nome científico } & \multirow{2}{*}{ Família } & \multicolumn{3}{|c|}{ Quantidade (por proprietário) } \\
\hline & & & SAF 4 & SAF 8 & SAF 16 \\
\hline \multicolumn{6}{|c|}{ Hortícolas e olerícolas } \\
\hline Açafrão & Crocus sativus & Iridaceae & & 30 & \\
\hline Batata-doce & Ipomoea batatas & Convolvulaceae & & 100 & \\
\hline Gengibre & Zingiber officinale & Zingiberaceae & & 50 & \\
\hline Inhame & Discorea sp. & Discoreaceae & 100 & 300 & 2.000 \\
\hline Mandioca & Manihot esculenta & Euphorbiaceae & 6.048 & 3.500 & 5.000 \\
\hline Feijão & Phaseolus vulgaris & Fabaceae & & 1.800 & 2.500 \\
\hline Milho & Zea mays & Poaceae & & & 3.000 \\
\hline Abobrinha & Cucurbita pepo & Cucurbitaceae & 100 & 300 & \\
\hline Alface & Lectuca sativa & Asteraceae & & 100 & 120 \\
\hline Beterraba & Beta sp. & Amarantaceae & & 150 & \\
\hline Cebola & Allium cepa & Alliaceae & & & 15 \\
\hline Chuchu & Sechium edule & Cucurbitaceae & 10 & 40 & \\
\hline Couve & Brassica oleracea & Brassicaceae & & 16 & 15 \\
\hline Jiló & Solanum gilo & Solanaceae & & & 15 \\
\hline Melancia & Cintrillus lanatus & Cucurbitaceae & & 20 & \\
\hline Pepino & Cucumis sativus & Cucurbitaceae & & 200 & 50 \\
\hline Pimenta-cumbari & Capsicum sp. & Solanaceae & 14 & & 10 \\
\hline Pimenta-do-reino & Piper nigrum & Piperaceae & & & 6 \\
\hline Rabanete & Raphanus sativus & Brassicaceae & & 300 & \\
\hline Rúcula & Eruca sativa & Brassicaceae & & 100 & 15 \\
\hline Salsa & Petroselinum crispum & Umbelliferae & & 50 & 15 \\
\hline Tomate & Solanum lycopersicum & Solanaceae & & 150 & \\
\hline \multicolumn{6}{|c|}{ Adubação verde } \\
\hline Cana & Saccharum sp. & Poaceae & 3.000 & 1.500 & 200 \\
\hline Citronela & Cymbopogon sp. & Poaceae & & 1 & \\
\hline Crotalária & Crotalaria sp. & Fabaceae & 200 & 100 & \\
\hline Feijão-de-porco & Canavalia ensiformis & Fabaceae & 100 & & 3.000 \\
\hline Guandu & Vigna unguiculata & Fabaceae & 10.000 & 50.000 & 8.000 \\
\hline Ibiscus & Hibiscus sp. & Malvaceae & & 2 & \\
\hline Mamona & Ricinus communis & Euphorbiaceae & 2.000 & 10 & 100 \\
\hline Mucuna & Mucuna sp. & Fabaceae & 30 & 300 & 6 \\
\hline Taioba & Xanthosoma sagittifolium & Araceae & & 150 & \\
\hline Urucum & Bixa orellana & Bixaceae & 300 & 1.500 & 50 \\
\hline
\end{tabular}


Tabela 4. Quantidade total de espécies e de plantas cultivadas nos SAF multiestrata dos três produtores avaliados em Barra do Turvo, SP, segundo seus diferentes usos.

\begin{tabular}{|c|c|c|c|c|c|c|c|c|c|c|c|c|}
\hline & \multicolumn{3}{|c|}{ Indivíduos ano $^{-1}$} & \multicolumn{3}{|c|}{ Espécies } & \multicolumn{3}{|c|}{ Famílias } & \multicolumn{3}{|c|}{$\begin{array}{c}\% \text { indivíduos } \\
\text { (em relação ao total) }\end{array}$} \\
\hline & SAF 4 & SAF 8 & SAF 16 & SAF 4 & SAF 8 & SAF 16 & SAF 4 & SAF 8 & SAF 16 & SAF 4 & SAF 8 & SAF 16 \\
\hline Madeireiras & 3.175 & 6.603 & 869 & 22 & 39 & 41 & 15 & 24 & 22 & 21,1 & 44,2 & 21,7 \\
\hline Fruteiras & 4.754 & 3.037 & 360 & 29 & 45 & 25 & 11 & 18 & 16 & 31,6 & 20,3 & 9,0 \\
\hline Palmeiras & 4.229 & 3.975 & 1.953 & 6 & 5 & 5 & 1 & 1 & 1 & 28,1 & 26,6 & 48,8 \\
\hline Hortícolas / Olerícolas & 1.568 & 901 & 798 & 5 & 17 & 13 & 4 & 12 & 11 & 10,4 & 6,0 & 19,9 \\
\hline Adubação verde & 1.333 & 433 & 22 & 7 & 9 & 6 & 4 & 6 & 4 & 8,8 & 2,9 & 0,6 \\
\hline Total & 15.059 & 14.949 & 4.002 & 69 & 125 & 90 & 35 & 61 & 54 & 100,0 & 100,0 & 100,0 \\
\hline Área ocupada pelo SAF (ha) & 2,42 & 3,18 & 3,00 & \multicolumn{6}{|c|}{ Densidade (madeireiras $\mathrm{m}^{-2}$ ) } & 0,52 & 1,66 & 0,46 \\
\hline Densidade (indivíduos. $\mathrm{m}^{-2}$ ) & 2,49 & 3,76 & 2,13 & \multicolumn{6}{|c|}{ Densidade (palmeiras $\mathrm{m}^{-2}$ ) } & 0,70 & 1,00 & 1,04 \\
\hline
\end{tabular}

Nas áreas ocupadas pelas capoeiras, as famílias de maior área basal foram: Fabaceae (10); Lauraceae (5); Myrtaceae (4); Euphorbiaceae e Moraceae (3); e Annonaceae, Arecaceae, Rubiaceae e Verbenaceae (duas espécies cada). Foram observados 3.626 ind. ha ${ }^{-1}$, de 45 espécies e 21 famílias (Tabela 2), com destaque para a Casearia sylvestris (cafezeiro-bravo), presente em todas as parcelas amostradas nesse sistema.

Nas áreas de agricultura convencional com cultivo de espécies herbáceas (abóbora e maracujá) não foram registrados indivíduos de porte arbóreo. Há que se registrar, inclusive, que a área ocupada pelo plantio de abóbora deve ser imediatamente recuperada por se tratar de uma área de preservação permanente (APP) ciliar, desmatada para a conversão em plantio agrícola. $\mathrm{Na}$ área de pupunha (Bactris gasipaes), todos os indivíduos corresponderam a esta espécie comercial, enquanto que nas pastagens foi observado um exemplar único de Psidium guajava na pastagem pouco degradada (Tabela 2). Estes resultados evidenciam os efeitos negativos da alta intensidade de manejo de sistemas convencionais (monocultivos) sobre a biodiversidade.
Dentre as plantas germinadas, foi observada a ocorrência de 102 espécies distribuídas em 47 famílias (Tabela 5). As famílias que apresentaram maior amplitude de ocorrência foram Asteraceae, Cyperaceae, Euphorbiaceae, Fabaceae e Poaceae, presentes em todos os sistemas de uso da terra avaliados.

Nos sistemas agrícolas, as famílias mais representativas foram Euphorbiaceae, Lamiaceae e Poaceae, totalizando 19 espécies e 15 famílias. Nas pastagens predominaram Fabaceae, Asteraceae e Poaceae, com um total de 27 espécies de 14 famílias. Nos SAF e nas capoeiras foram observadas 33 famílias para cada um desses sistemas, sendo 62 espécies nos SAF (com predominância de Poaceae, Asteraceae, Euphorbiaceae e Fabaceae) e 58 espécies nas capoeiras (com destaque para Fabaceae e Asteraceae). Curiosamente, foi observada a ocorrência de Musa paradisiaca (banana) no sub-bosque da capoeira com 20 anos de pousio (já averbada como reserva legal) em decorrência da permanência de exemplares de antigo cultivo em áreas menos sombreadas dentro da capoeira. 
Tabela 5. Famílias e espécies registradas na regeneração/sub-bosque dos diferentes sistemas de uso da terra (agricultura convencional, agrofloresta, capoeira e pastagem), em Barra do Turvo, SP.

\begin{tabular}{|c|c|c|c|c|c|c|c|c|c|c|c|c|c|c|}
\hline \multirow{3}{*}{ Família } & \multirow{3}{*}{ Espécie } & \multirow{3}{*}{ GE } & \multicolumn{12}{|c|}{ Sistema deuso da terra (SUT) } \\
\hline & & & \multicolumn{3}{|c|}{$\mathbf{A C}$} & \multicolumn{3}{|c|}{ SAF } & \multicolumn{3}{|c|}{$\mathbf{C P}$} & \multicolumn{3}{|c|}{ PT } \\
\hline & & & $\mathbf{A B}$ & MA & PU & $\begin{array}{c}\text { SAF } \\
4\end{array}$ & $\begin{array}{c}\text { SAF } \\
8\end{array}$ & $\begin{array}{c}\text { SAF } \\
16 \\
\end{array}$ & C5 & $\mathbf{C 2 0}$ & C30 & PDE & PMD & PPD \\
\hline Acanthaceae & Ruellia brevifolia (Pohl.) Ezcur & & & & & & & $\mathrm{X}$ & & & & & & \\
\hline Amaranthaceae & Amaranthus deflexus L. & & $\mathrm{X}$ & $\mathrm{X}$ & & & & & & & & & & \\
\hline Annonaceae & Rollinia sericea (R. E. Fries) R. E. Fries & ST & & & & $X$ & & & & $\mathrm{X}$ & $\mathrm{X}$ & & & \\
\hline \multirow{3}{*}{ Arecaceae } & Bactris gasipaes Kunth & EX & $\mathrm{X}$ & & & $\mathrm{X}$ & & & & & & & & \\
\hline & Euterpe edulis Mart. & $\mathrm{CL}$ & & & & $\mathrm{X}$ & $\mathrm{X}$ & $\mathrm{X}$ & & & $\mathrm{X}$ & & & \\
\hline & Syagrus romanzoffiana (Cham.) Glass. & SI & & & & & & & $\mathrm{X}$ & & & & & \\
\hline \multirow{6}{*}{ Asteraceae } & Baccharis sp. & $P$ & & & & $\mathrm{X}$ & & & $\mathrm{X}$ & & & & & \\
\hline & Bidens pilosa $\mathrm{L}$. & & & $\mathrm{X}$ & & $\mathrm{X}$ & & & & & & & & \\
\hline & Mikania cordiflora (L.f.) Willd. & & & & & $\mathrm{X}$ & $\mathrm{X}$ & $X$ & $\mathrm{X}$ & & & & $\mathrm{X}$ & \\
\hline & Solidago chilensis Meyen & & & & & & & & $\mathrm{X}$ & & & $\mathrm{X}$ & & \\
\hline & Sonchus oleraceus L. & & & & & & $\mathrm{X}$ & & & & & & & \\
\hline & Vernonia polyanthes Less. & & & & & & $\mathrm{X}$ & & $X$ & & & $X$ & $\mathrm{X}$ & $X$ \\
\hline Bambusaceae & Bambusa sp. & EX & & & & & & & & & $\mathrm{X}$ & & & \\
\hline \multirow{2}{*}{ Bignoniaceae } & $\begin{array}{l}\text { Macfadyena ungüis-cati (L.) A. H. } \\
\text { Gentry }\end{array}$ & & & & & & & $\mathrm{X}$ & $\mathrm{X}$ & & & & & \\
\hline & $\begin{array}{l}\text { Sparattosperma leucanthum (Vell.) } \\
\text { K. Schum }\end{array}$ & & & & & & & $\mathrm{X}$ & & & $\mathrm{X}$ & & & \\
\hline Bromeliaceae & Ananas sp. & & & & & $\mathrm{X}$ & & & & & & & & \\
\hline Cecropiaceae & Cecropia glaziovi Snethlage & $P$ & & & & & & $\mathrm{X}$ & & & & & & \\
\hline \multirow{2}{*}{ Commelinaceae } & Commelina benghalensis L. & & & $\mathrm{X}$ & & $\mathrm{X}$ & & & $\mathrm{X}$ & & & & & \\
\hline & Commelina sp. & & & & & & & & & & $\mathrm{X}$ & & & \\
\hline \multirow{3}{*}{ Convolvulaceae } & Ipomoea acuminata Roem. et. Sch. & & & & & & $\mathrm{X}$ & & & & & & & \\
\hline & Ipomoea batatas (L.) Lam. & & & & & $\mathrm{X}$ & $\mathrm{X}$ & & & & & & & \\
\hline & Ipomoea sp. & & $\mathrm{X}$ & $\mathrm{X}$ & & & & & & & & & & \\
\hline \multirow{2}{*}{ Cyperaceae } & Cyperus meyenianus Kunth & & $\mathrm{X}$ & $\mathrm{X}$ & $\mathrm{X}$ & $\mathrm{X}$ & $\mathrm{X}$ & & $\mathrm{X}$ & & & $\mathrm{X}$ & & $\mathrm{X}$ \\
\hline & Scleria pterota Presl. & & & & & & $\mathrm{X}$ & $\mathrm{X}$ & $\mathrm{X}$ & $\mathrm{X}$ & & & & \\
\hline \multirow{7}{*}{ Euphorbiaceae } & Alchornea triplinervia (Spreng.) M. Arg. & SI & & & & & & $\mathrm{X}$ & & & & & & \\
\hline & Chamaesyce hirta (L.) Millsp. & & $\mathrm{X}$ & $\mathrm{X}$ & $\mathrm{X}$ & $\mathrm{X}$ & & & & & & & & $\mathrm{X}$ \\
\hline & Croton floribundus Spreng. & $\mathrm{P}$ & & & & & & $\mathrm{X}$ & $\mathrm{X}$ & & & & & \\
\hline & Croton sp. & $\mathrm{P}$ & & & $\mathrm{X}$ & & & & & & & & & \\
\hline & Croton glandulosus L. & & & & & & & & & & & & & $X$ \\
\hline & Manihot esculenta & & & & & $\mathrm{X}$ & $\mathrm{X}$ & & $\mathrm{X}$ & & & & & \\
\hline & Phyllantus niruri L. & & & $\mathrm{X}$ & & $\mathrm{X}$ & & & & & & & & \\
\hline Equizeaceae & Lygodium sp. & & & & & & $\mathrm{X}$ & $\mathrm{X}$ & & $\mathrm{X}$ & $\mathrm{X}$ & & & \\
\hline \multirow{2}{*}{ Fabaceae } & Bauhinia forficata Link & $P$ & & & & & & & & $\mathrm{X}$ & & & & \\
\hline & Cajanus cajan (L. Millsp.) & & & & & $\mathrm{X}$ & & & & & & & & \\
\hline
\end{tabular}


Tabela 5. Continuação.

\begin{tabular}{|c|c|c|c|c|c|c|c|c|c|c|c|c|c|c|}
\hline \multirow{3}{*}{ Família } & \multirow{3}{*}{ Espécie } & \multirow{3}{*}{ GE } & \multicolumn{12}{|c|}{ Sistema deuso da terra (SUT) } \\
\hline & & & \multicolumn{3}{|c|}{ AC } & \multicolumn{3}{|c|}{ SAF } & \multicolumn{3}{|c|}{$\mathbf{C P}$} & \multicolumn{3}{|c|}{ PT } \\
\hline & & & $\mathbf{A B}$ & MA & PU & $\begin{array}{c}\text { SAF } \\
4\end{array}$ & $\begin{array}{c}\text { SAF } \\
\mathbf{8}\end{array}$ & $\begin{array}{c}\text { SAF } \\
16\end{array}$ & C5 & $\mathbf{C 2 0}$ & C30 & PDE & PMD & PPD \\
\hline \multirow{13}{*}{ Fabaceae } & $\begin{array}{l}\text { Chamaecrista nictitans subsp. } \\
\text { pattelaria (Collad.) H. S. Irwin \& } \\
\text { Barneby }\end{array}$ & & & & & & & & & & & & & $\mathrm{X}$ \\
\hline & Crotalaria incana $\mathrm{L}$. & & & & & & & & & & & $\mathrm{X}$ & & \\
\hline & Crotalaria lanceolata E. Mey. & & & & & & & & & & & & & $\mathrm{X}$ \\
\hline & Desmodium adscendens (Sw.) DC. & & & & & & $\mathrm{X}$ & $\mathrm{X}$ & $\mathrm{X}$ & $\mathrm{X}$ & & $\mathrm{X}$ & $\mathrm{X}$ & $\mathrm{x}$ \\
\hline & $\begin{array}{l}\text { Glycine wightii (Graham ex Wright } \\
\text { \& Arn.) Verdc. }\end{array}$ & & $\mathrm{X}$ & & & $\mathrm{X}$ & $\mathrm{X}$ & $\mathrm{X}$ & $\mathrm{X}$ & $\mathrm{X}$ & & $\mathrm{X}$ & & \\
\hline & Inga marginata Willd. & $\mathrm{CL}$ & & & & & & $\mathrm{X}$ & & $\mathrm{X}$ & $\mathrm{X}$ & & & \\
\hline & Lonchocarpus sp. & SI & & & & & & & & & $\mathrm{X}$ & & & \\
\hline & Machaerium nyctitans (Vell.) Benth & $\mathrm{P}$ & & & & & & & $\mathrm{X}$ & $\mathrm{X}$ & & $\mathrm{X}$ & & \\
\hline & Machaerium stipitatum (DC.) Vog. & SI & & & & & & & $\mathrm{X}$ & $\mathrm{X}$ & & & & \\
\hline & Mimosa pudica $\mathrm{L}$. & & & & & & & & & & & $\mathrm{X}$ & & \\
\hline & Senna multijuga (Rich.) Irwin et Barn. & SI & & & & & & & $\mathrm{X}$ & $\mathrm{X}$ & & & & \\
\hline & $\begin{array}{l}\text { Senna obtusifolia (L.) H. S. Irwin } \\
\text { \& Barneby }\end{array}$ & & & & & & & & $\mathrm{X}$ & & & & & \\
\hline & Vigna sinensis Endl. & & & & & & & $\mathrm{X}$ & & & & & & \\
\hline Flacourtiaceae & Casearia sylvestris $\mathrm{Sw}$. & SI & & & & & & & $\mathrm{X}$ & & & & & \\
\hline Gleicheniaceae & Dicranopteris pectinata (Willd.) Und. & & & & & & & & $\mathrm{X}$ & & & & & \\
\hline \multirow{3}{*}{ Lamiaceae } & Hyptis brevipes Poit. & & & & & $\mathrm{X}$ & & & $\mathrm{X}$ & & & & & \\
\hline & Leonurus sibiricus L. & & $\mathrm{X}$ & & & & & & & & & & & \\
\hline & Stachys arvensis $\mathrm{L}$. & & $\mathrm{X}$ & & & & & & & & & & & \\
\hline Lauraceae & Nectandra grandiflora Nees & ST & & & & & $\mathrm{X}$ & & $\mathrm{X}$ & & $\mathrm{X}$ & & & \\
\hline Liliaceae & Smilax brasiliensis Spreng & & & & & $\mathrm{X}$ & & & $\mathrm{X}$ & & $\mathrm{X}$ & & & \\
\hline Lythraceae & Cuphea racemosa (L.f.) Spreng. & & & & & & & & & & & $\mathrm{X}$ & & \\
\hline \multirow{3}{*}{ Malvaceae } & $\begin{array}{l}\text { Malvastrum coromandelianum (L.) } \\
\text { Garcke }\end{array}$ & & & & & $\mathrm{X}$ & & & $\mathrm{X}$ & $\mathrm{X}$ & & $\mathrm{X}$ & $\mathrm{X}$ & \\
\hline & Sida cordiflora $\mathrm{L}$ & & & & & $\mathrm{X}$ & & & $\mathrm{X}$ & & & & & \\
\hline & Sida carpinifolia L.f. & & & & & & & & & & & $\mathrm{X}$ & & \\
\hline Marantaceae & Thalia geniculata $\mathrm{L}$. & & & & & & & & $\mathrm{X}$ & $\mathrm{X}$ & $\mathrm{X}$ & & & \\
\hline \multirow{2}{*}{ Melastomataceae } & Tibouchina mutabilis Cong. & $\mathrm{P}$ & & & & & $\mathrm{X}$ & & & & & & & \\
\hline & Miconia sp. & & & & & & $\mathrm{X}$ & $\mathrm{X}$ & $\mathrm{X}$ & $\mathrm{X}$ & $\mathrm{X}$ & & $\mathrm{X}$ & \\
\hline Meliaceae & Guarea kunthiana A. Juss. & SI & & & & & & & & & $\mathrm{X}$ & & & \\
\hline Moraceae & $\begin{array}{l}\text { Sorocea bonplandii (Baill.) Burger, } \\
\text { Lanjow \& Boer }\end{array}$ & SI & & & & & & & & & $\mathrm{X}$ & & & \\
\hline Musaceae & Musa paradisiaca & EX & & & & & & & & $\mathrm{X}$ & & & & \\
\hline Myrsinaceae & $\begin{array}{l}\text { Rapanea umbellata (Mart. ex DC.) } \\
\text { Mez }\end{array}$ & SI & & & & & & $\mathrm{X}$ & & & & & & \\
\hline \multirow{4}{*}{ Myrtaceae } & Eugenia uniflora L. & ST & & & & & $\mathrm{X}$ & & & & & & & \\
\hline & Myrcia rostrata DC. & & & & & & & & $\mathrm{X}$ & & & & & \\
\hline & Psidium guajava $\mathrm{L}$. & EX & & & $\mathrm{X}$ & & & & & & & $\mathrm{X}$ & & $\mathrm{X}$ \\
\hline & Psidium sp. & $\mathrm{CL}$ & & & & & & $\mathrm{X}$ & $\mathrm{X}$ & $\mathrm{X}$ & $\mathrm{X}$ & & & \\
\hline Oxalidaceae & Oxalis corymbosa DC. & & & $\mathrm{X}$ & $\mathrm{X}$ & $\mathrm{X}$ & & & & & & $\mathrm{X}$ & & \\
\hline
\end{tabular}


Tabela 5. Continuação.

\begin{tabular}{|c|c|c|c|c|c|c|c|c|c|c|c|c|c|c|}
\hline \multirow{3}{*}{ Família } & \multirow{3}{*}{ Espécie } & \multirow{3}{*}{ GE } & \multicolumn{12}{|c|}{ Sistema deuso da terra (SUT) } \\
\hline & & & \multicolumn{3}{|c|}{$\mathbf{A C}$} & \multicolumn{3}{|c|}{ SAF } & \multicolumn{3}{|c|}{$\mathbf{C P}$} & \multicolumn{3}{|c|}{ PT } \\
\hline & & & $\mathbf{A B}$ & MA & PU & $\begin{array}{c}\text { SAF } \\
4\end{array}$ & $\begin{array}{c}\text { SAF } \\
8\end{array}$ & $\begin{array}{c}\text { SAF } \\
16\end{array}$ & C5 & $\mathrm{C20}$ & C30 & PDE & PMD & PPD \\
\hline Passifloraceae & Passiflora edulis Sims & & & & & & & & $\mathrm{X}$ & & & & & \\
\hline Piperaceae & Piper aduncum L. & $\mathrm{SC}$ & & & & & & $\mathrm{X}$ & $\mathrm{X}$ & $\mathrm{X}$ & & & & \\
\hline \multirow{8}{*}{ Poaceae } & Brachiaria platyphylla (Griseb.) Nash & & & & & & & & & & $\mathrm{X}$ & & & \\
\hline & Brachiaria sp. & & & & & & $\mathrm{X}$ & & & & & $\mathrm{X}$ & $\mathrm{X}$ & $\mathrm{X}$ \\
\hline & Digitaria horizontalis Willd. & & & & & & & $\mathrm{X}$ & & & & & & \\
\hline & Imperata brasiliensis Trin. & & & & & & $\mathrm{X}$ & $\mathrm{X}$ & & & & $\mathrm{X}$ & & \\
\hline & Ichnantus sp. & & & & & & & $\mathrm{X}$ & $\mathrm{X}$ & $\mathrm{X}$ & $\mathrm{X}$ & & & \\
\hline & Leptochloa virgata (L.) P. Beauv. & & $\mathrm{X}$ & $\mathrm{X}$ & $\mathrm{X}$ & $\mathrm{X}$ & & & & & & & & \\
\hline & Panicum maximum Jacq. & & $\mathrm{X}$ & & & & $\mathrm{X}$ & & & & & $\mathrm{X}$ & & \\
\hline & Setaria geniculata (Lam.) Beauv. & & & & & $\mathrm{X}$ & & & $\mathrm{X}$ & & & & & \\
\hline Polygonaceae & Polygonum convolvulus $\mathrm{L}$. & & & & & & & & $\mathrm{X}$ & $\mathrm{X}$ & & & & \\
\hline \multirow{2}{*}{ Polypodiaceae } & Microgramma sp. & & & & & & & $\mathrm{X}$ & & $\mathrm{X}$ & $\mathrm{X}$ & & & \\
\hline & Polypodium sp. & & & & & & $\mathrm{X}$ & & & $\mathrm{X}$ & & & & \\
\hline Portulaccaceae & Talinum paniculatum (Jacq.) Gaertn & & $\mathrm{X}$ & & & & & $\mathrm{X}$ & & & & & & \\
\hline Pteridaceae & Pteridium aquilinum (L.) Kuhn & & & & & & & $\mathrm{X}$ & & & & & & \\
\hline Rosaceae & Rubus rosifolius $\mathrm{Sm}$. & & & & & & & $\mathrm{X}$ & & & & & & \\
\hline \multirow{2}{*}{ Rubiaceae } & Coffea arabica $\mathrm{L}$. & EX & & & & $\mathrm{X}$ & & & & & & & & \\
\hline & Rudgea jasminioides (Cham.) Müll. Arg. & SI & & & & & & $\mathrm{X}$ & & $\mathrm{X}$ & $\mathrm{X}$ & & & \\
\hline Rutaceae & Citrus reticulata Blanco & $\mathrm{CL}$ & & & & & & $\mathrm{X}$ & & & & & & \\
\hline \multirow{3}{*}{ Sapindaceae } & Allophylus guaraniticus Camb. & & & & & & & $\mathrm{X}$ & $\mathrm{X}$ & & & & & \\
\hline & Cardiospermum halicacabum L. & & & & & & $\mathrm{X}$ & & & & $X$ & & & \\
\hline & Cupania vernalis Camb. & SI & & & & & & $\mathrm{X}$ & & & $\mathrm{X}$ & & & \\
\hline \multirow{3}{*}{ Solanaceae } & Solanum asperolanatum Ruiz \& Pav. & & & & & & & & $\mathrm{X}$ & $\mathrm{X}$ & & & & \\
\hline & Solanum viarum Dunal. & & & & & & & & $\mathrm{X}$ & & & & & \\
\hline & Solanum sp. & & & $\mathrm{X}$ & $\mathrm{X}$ & $\mathrm{X}$ & & $\mathrm{X}$ & $\mathrm{X}$ & $\mathrm{X}$ & & & & \\
\hline \multirow[b]{2}{*}{ Sterculiaceae } & Waltheria indica $\mathrm{L}$. & & & & & & & & & & & & $\mathrm{X}$ & $\mathrm{X}$ \\
\hline & $\begin{array}{l}\text { Waltheria tomentosa (J. R. Forster } \\
\& \text { G. Forster) H. St. John }\end{array}$ & & & & & & & & & & & $\mathrm{X}$ & $\mathrm{X}$ & $\mathrm{X}$ \\
\hline Tiliaceae & Triumfetta semitriloba Jacq. & & & & & & & & & $\mathrm{X}$ & & $\mathrm{X}$ & $\mathrm{X}$ & $\mathrm{X}$ \\
\hline Thelypteridaceae & $\begin{array}{l}\text { Thelypteris dentate (Forssk.) E. P. } \\
\text { St. Hill. }\end{array}$ & & & & & & & & $\mathrm{X}$ & & & $\mathrm{X}$ & & $\mathrm{X}$ \\
\hline \multirow[b]{2}{*}{ Verbenaceae } & Lantana trifolia $\mathrm{L}$. & & & & & & & & & & & & $\mathrm{X}$ & \\
\hline & $\begin{array}{l}\text { Stachytarpheta elatior Schrad. Ex } \\
\text { Schult. }\end{array}$ & & $\mathrm{X}$ & & & & & $\mathrm{X}$ & & & & & & \\
\hline Zingiberaceae & Hedychium coronarium J. Konig & & & & & & & $\mathrm{X}$ & $\mathrm{X}$ & $\mathrm{X}$ & & & & \\
\hline
\end{tabular}

AB (plantio de abóbora); MA (plantio de maracujá); PU (plantio de pupunha); SAF 4 (jovem), SAF 8 (intermediário); SAF 16 (maduro); C5 (capoeira de 5 anos averbada como RL); C20 (capoeira de 20 anos averbada como RL); C30 (capoeira com mais de 30 anos); PDE (pastagem muito degradada); PMD (pastagem medianamente degradada); PPD (pastagem pouco degradada). 


\section{Grupo ecológico das espécies encontradas nos SUT estudados}

Entre os indivíduos cujo DAP/CAP foi mensurado houve uma predominância, analisando-se todos os sistemas estudados, de secundárias iniciais e pioneiras strito sensu que, juntamente com as exóticas, corresponderam a quase $80 \%$ das espécies encontradas (Tabela 2).

O critério para analisar exóticas, independente do seu estágio sucessional foi para salientar a ocorrência deste tipo de vegetação, tanto nas áreas produtivas quanto naquelas em regeneração (capoeiras). Foram observadas espécies exóticas em duas das áreas de capoeira, avaliadas como C5 e C20, legalmente averbadas como RL, mas, segundo a legislação vigente (Brasil, 2009), só deveriam conter espécies exóticas em caráter temporário.

Nos sistemas agrícolas e pastoris, $100 \%$ das espécies encontradas foram classificadas como exóticas. Nos SAF predominaram as espécies exóticas, seguidas das pioneiras e das secundárias iniciais $(80,4 \%)$, enquanto que nas capoeiras predominaram espécies secundárias iniciais e pioneiras, que totalizaram $77,3 \%$ das espécies. Portanto, ambos os sistemas, do ponto de vista sucessional, apresentam-se imaturos. A predominância de espécies exóticas nos sistemas pastoris e nos SAF são facilmente explicados pelo caráter produtivo desses sistemas. Contudo, mesmo que as capoeiras aqui avaliadas sejam sistemas naturais em regeneração, a ocorrência de espécies exóticas stricto sensu Artocarpus heterophyllus (jaca) e Citrus sp. (limão-rosa), respectivamente nas capoeiras de menor e de maior tempo de pousio, mostra a facilidade de adaptação às áreas em processo de recuperação da vegetação nativa, caso das áreas de RL, devidamente reconhecidas pelo órgão ambiental competente.

Do total das espécies com DAP $\geq 5 \mathrm{~cm}$, observa-se que no SAF mais novo (4 anos) só foram observadas espécies pioneiras, exóticas e secundárias iniciais, justamente pela maior disponibilidade de luz direta naquelas parcelas, inclusive em função das práticas de manejo agroflorestal, com a predominância de plantio de espécies hortícolas e culturas anuais. Com o amadurecimento dos SAF (8 e 16 anos) pode-se observar, além do aumento de espécies, o desenvolvimento gradual de espécies secundárias tardias e climácicas, bem como, entre as exóticas, da presença de espécies de porte arbóreo (Tabela 2). Este comportamento é similar ao que ocorre nas capoeiras, evidenciando o caráter sucessional de manejo dessas áreas (Götsch, 1997), mas também é reflexo da tomada de decisão do produtor agroflorestal local e do planejamento da propriedade rural, conforme será discutido mais adiante.

\section{Parâmetros fitossociológicos das áreas de SAF e capoeira}

Nas áreas de SAF, a banana (Musa paradisiaca) foi a espécie que apresentou valor mais elevado de VI (valor de importância), seguida da juçara (Euterpe edulis), embaúba (Cecropia glaziovi), grandiúva (Trema micrantha) e goiabeira (Psidium guajava) (Tabela 6), evidenciando a bananeira e a juçara como as espécies mais importantes, para a obtenção de produtos em médio e longo prazos, respectivamente, no modelo de SAF adotado na Barra do Turvo, SP. Isolando-se o efeito das espécies exóticas, as espécies com maiores valores de VI, no conjunto dos SAF, em ordem decrescente, são: Euterpe edulis, Cecropia glaziovi, Trema micrantha, Nectandra lanceolata, Citharexyllum myrianthum, Machaerium stiptatum, Rapanea umbellata, Tibouchina mutabilis e Senna multijuga, comuns às áreas de capoeira, algumas das quais também presentes entre as plantas da regeneração (E. edulis, M. stiptatum e $S$. multijuga), ratificando a importância desse modelo de SAF na recuperação da biodiversidade local, quer seja pelo plantio das espécies florestais nativas, ou ao permitir sua regeneração.

Nas capoeiras, as espécies que apresentaram maior VI foram, em ordem decrescente, o cafezeiro-bravo (Casearia sylvestris), pau-sangue (Croton floribundus), Psidium sp., queima-casa (Bathysa meridionalis) e tapiá (Alchornea triplinervia) (Tabela 6).

Nas capoeiras mais jovens (C5 e C20) predominam espécies heliófilas, mesmo que algumas delas possam apresentar plasticidade ecológica para habitar ambientes com diferentes graus de disponibilidade de luz, tais como Machaerium nictitans, Casearia sylvestris, Senna multijuga e Andira legalis. Por outro lado, na capoeira com maior tempo de pousio (C30), predominam espécies com demandas de iluminação difusa (Matayba elaegnoides), de sub-bosque (Sorocea bonplandii), umbrófilas (Bathysa meridionalis), secundárias tardias a climáxicas (Euterpe edulis), fato este que está intimamente ligado à maturação da sucessão florestal (Budowski, 1965). 
Tabela 6. Índice de valor de Importância para as principais espécies (IVI $\geq 10 \%$ ) nos sistemas agroflorestais e capoeiras estudados.

\begin{tabular}{|c|c|c|c|c|c|}
\hline \multirow[t]{2}{*}{ Propriedade } & \multirow[t]{2}{*}{ Espécie } & $\begin{array}{l}\text { Densidade } \\
\text { relativa }\end{array}$ & $\begin{array}{c}\text { Dominância } \\
\text { relativa }\end{array}$ & $\begin{array}{c}\text { Frequência } \\
\text { relativa }\end{array}$ & \multirow[t]{2}{*}{ IVI } \\
\hline & & \multicolumn{3}{|c|}{$\%$} & \\
\hline \multirow{5}{*}{ SAF 4} & Musa paradisiaca & 53,3 & 69,9 & 11,5 & 134,8 \\
\hline & Trema micrantha & 11,4 & 8,4 & 7,7 & 27,5 \\
\hline & Cecropia galaziovi & 4,8 & 3,5 & 11,5 & 19,9 \\
\hline & Machaerium stipitatum & 3,8 & 2 & 7,7 & 13,5 \\
\hline & Carica papaya & 2,9 & 1,1 & 7,7 & 11,7 \\
\hline \multirow{6}{*}{ SAF 8} & Musa paradisiaca & 55,7 & 59,9 & 12,5 & 128,1 \\
\hline & Euterpe edulis & 23,5 & 9,7 & 4,2 & 37,3 \\
\hline & Psidium guajava & 2,6 & 4,1 & 8,3 & 15,0 \\
\hline & Lonchocarpus sp. & 2,6 & 2 & 8,3 & 13 \\
\hline & Persea americana & 0,9 & 6,2 & 4,2 & 11,3 \\
\hline & Eugenia uniflora & 0,9 & 5,8 & 4,2 & 10,9 \\
\hline \multirow{9}{*}{ SAF 16} & Musa paradisiaca & 29,8 & 34,3 & 4,8 & 68,9 \\
\hline & Cecropia galaziovi & 7,4 & 6,7 & 4,8 & 18,9 \\
\hline & Euterpe edulis & 9,1 & 5 & 4,8 & 18,8 \\
\hline & Rapanea umbellata & 4,1 & 4,2 & 4,8 & 14 \\
\hline & Piper aduncum & 7,4 & 2,4 & 2,4 & 12,2 \\
\hline & Psidium guajava & 3,3 & 3,3 & 4,8 & 11,3 \\
\hline & Nectandra lanceolata & 2,5 & 3,9 & 4,8 & 11,1 \\
\hline & Artocarpus heterophyllus & 4,1 & 4,5 & 2,4 & 11 \\
\hline & Tibouchina mutabilis & 2,5 & 2,8 & 4,8 & 10 \\
\hline \multirow{5}{*}{$\begin{array}{c}\text { SAF } \\
\text { multiestrato } \\
\text { (média) }\end{array}$} & Musa paradisiaca & 45,8 & 55,2 & 8,7 & 109,7 \\
\hline & Euterpe edulis & 11,1 & 4,6 & 3,3 & 19 \\
\hline & Cecropia galaziovi & 4,1 & 3,5 & 5,4 & 13 \\
\hline & Trema micrantha & 3,8 & 3,2 & 3,3 & 10,3 \\
\hline & Psidium guajava & 2,4 & 2,4 & 5,4 & 10,2 \\
\hline \multirow{7}{*}{$\mathrm{C} 5$} & Croton floribundus & 30,1 & 35,6 & 7,3 & 72,96 \\
\hline & Machaerium nyctitans & 5,3 & 10,2 & 7,3 & 22,84 \\
\hline & Casearia sylvestris & 8 & 3,4 & 7,3 & 18,65 \\
\hline & Senna multijuga & 8 & 3,3 & 4,9 & 16,14 \\
\hline & Psidium sp. & 6,2 & 1,5 & 7,3 & 15,02 \\
\hline & Rapanea umbellata & 2,7 & 6,2 & 2,4 & 11,30 \\
\hline & Andira legalis & 3,5 & 1,8 & 4,9 & 10,21 \\
\hline
\end{tabular}


Tabela 6. Continuação.

\begin{tabular}{|c|c|c|c|c|c|}
\hline \multirow[t]{2}{*}{ Propriedade } & \multirow[t]{2}{*}{ Espécie } & $\begin{array}{l}\text { Densidade } \\
\text { relativa }\end{array}$ & $\begin{array}{l}\text { Dominância } \\
\text { relativa }\end{array}$ & $\begin{array}{c}\text { Frequência } \\
\text { relativa }\end{array}$ & \multirow[t]{2}{*}{ IVI } \\
\hline & & \multicolumn{3}{|c|}{$\%$} & \\
\hline \multirow{11}{*}{$\mathrm{C} 20$} & Psidium sp. & 20,9 & 15,4 & 7,1 & 43,4 \\
\hline & Casearia sylvestris & 7,3 & 7,6 & 7,1 & 22,1 \\
\hline & Myrcia crassifolia & 4,2 & 10,6 & 4,8 & 19,5 \\
\hline & Bauhinia forficata & 5,2 & 5 & 7,1 & 17,3 \\
\hline & Machaerium stipitatum & 4,2 & 6,1 & 4,8 & 15,1 \\
\hline & Senna multijuga & 8,3 & 4,3 & 2,4 & 15,0 \\
\hline & Lonchocarpus sp. & 6,3 & 3,5 & 4,8 & 14,5 \\
\hline & Luehea divaricata & 2,1 & 8,7 & 2,4 & 13,2 \\
\hline & Rapanea umbellata & 2,1 & 4,8 & 4,8 & 11,7 \\
\hline & Machaerium nyctitans & 5,2 & 3,7 & 2,4 & 11,6 \\
\hline & Nectandra lanceolata & 4,2 & 1,5 & 4,8 & 10,4 \\
\hline \multirow{7}{*}{$\mathrm{C} 30$} & Bathysa meridionalis & 17,6 & 13,3 & 5,1 & 36,1 \\
\hline & Casearia sylvestris & 8,3 & 14,8 & 7,7 & 30,9 \\
\hline & Euterpe edulis & 17,6 & 4,5 & 7,7 & 29,7 \\
\hline & Guarea kunthiana & 7,4 & 14,6 & 5,1 & 27,1 \\
\hline & Alchornea triplinervia & 3,7 & 15,0 & 7,7 & 26,4 \\
\hline & Matayba elaegnoides & 5,6 & 5,1 & 2,6 & 13,2 \\
\hline & Sorocea bonplandii & 4,6 & 0,6 & 5,1 & 10,4 \\
\hline \multirow{8}{*}{$\begin{array}{l}\text { Capoeira } \\
\text { (média) }\end{array}$} & Casearia sylvestris & 7,9 & 9,9 & 7,4 & 25,2 \\
\hline & Croton floribundus & 10,7 & 9,2 & 2,5 & 22,4 \\
\hline & Psidium sp. & 8,5 & 4,5 & 4,9 & 18 \\
\hline & Bathysa meridionalis & 6 & 6,3 & 1,6 & 13,9 \\
\hline & Alchornea triplinervia & 1,6 & 7,1 & 3,3 & 12 \\
\hline & Euterpe edulis & 6,3 & 2,2 & 3,3 & 11,8 \\
\hline & Guarea kunthiana & 2,5 & 6,9 & 1,6 & 11 \\
\hline & Machaerium nyctitans & 3,5 & 3,6 & 3,3 & 10,4 \\
\hline
\end{tabular}

C5 (capoeira de 5 anos averbada como RL); C20 (capoeira de 20 anos averbada como RL); C30 (capoeira com mais de 30 anos). 
Tabela 7. Parâmetros fitossociológicos calculados a partir do levantamento arbóreo nas parcelas contendo agricultura convencional, agrofloresta e capoeira (área, densidade, área basal, volume, DAP e altura).

\begin{tabular}{|c|c|c|c|c|c|c|c|c|c|}
\hline & $\begin{array}{c}\text { Parcelas } \\
\text { amostradas }\end{array}$ & $\begin{array}{c}\text { Área total } \\
\text { amostrada } \\
\text { (ha) }\end{array}$ & Indivíduos & $\begin{array}{c}\text { Densidade } \\
\text { total } \\
\text { (ind. ha-1) }^{-1} \text {. }\end{array}$ & $\begin{array}{c}\text { Área } \\
\text { basal } \\
\left(\mathbf{m}^{2}\right)\end{array}$ & $\begin{array}{c}\text { Área } \\
\text { basal } \\
\text { (por ha) }\end{array}$ & $\begin{array}{c}\text { Volume } \\
\text { total } \\
\left(\mathbf{m}^{3}\right)\end{array}$ & $\begin{array}{l}\mathrm{DAP} \pm \text { d.p. }{ }^{1} \\
\quad(\mathrm{~cm})\end{array}$ & $\begin{array}{c}\mathrm{H} \pm \text { d.p. } \\
\text { (m) }\end{array}$ \\
\hline Geral & 21 & 0,675 & 749 & $1.109,6$ & 9,7 & 10,8 & 87,8 & $11,2 \pm 6,4$ & $6,4 \pm 3,7$ \\
\hline Agricultura & 3 & 0,225 & 90 & 400,0 & 0,7 & 3,1 & 3,1 & $9,4 \pm 3,0$ & $4,3 \pm 0,7$ \\
\hline PU & 3 & 0,075 & 90 & 1200,0 & 0,7 & 9,2 & 3,1 & $9,4 \pm 3,0$ & $4,3 \pm 0,7$ \\
\hline SAF-ME & 9 & 0,225 & 341 & $1.515,6$ & 3,5 & 15,5 & 20,3 & $10,4 \pm 4,7$ & $5,1 \pm 3,0$ \\
\hline SAF 4 & 3 & 0,075 & 105 & $1.400,0$ & 1,3 & 17,1 & 6,1 & $11,4 \pm 5,1$ & $4,7 \pm 2,6$ \\
\hline SAF 8 & 3 & 0,075 & 115 & $1.533,3$ & 1,1 & 14,2 & 5,9 & $9,9 \pm 4,5$ & $4,4 \pm 2,4$ \\
\hline SAF 16 & 3 & 0,075 & 121 & $1.613,3$ & 1,1 & 15,2 & 8,4 & $10,1 \pm 4,3$ & $6,2 \pm 3,4$ \\
\hline Capoeira & 9 & 0,225 & 317 & $1.408,9$ & 5,5 & 24,5 & 64,0 & $12,4 \pm 8,2$ & $8,4 \pm 3,9$ \\
\hline C5 & 3 & 0,075 & 113 & $1.506,7$ & 1,4 & 19,0 & 13,9 & $10,5 \pm 7,1$ & $7,5 \pm 3,2$ \\
\hline $\mathrm{C} 20$ & 3 & 0,075 & 96 & $1.280,0$ & 1,5 & 19,7 & 16,9 & $11,9 \pm 7,5$ & $8,4 \pm 3,9$ \\
\hline $\mathrm{C} 30$ & 3 & 0,075 & 108 & $1.440,0$ & 2,6 & 34,7 & 33,3 & $14,9 \pm 9,3$ & $9,2 \pm 4,5$ \\
\hline
\end{tabular}

(1) Média \pm desvio padrão; PU (plantio de pupunha); SAF 4 (jovem); SAF 8 (intermediário); SAF 16 (maduro); C5 (capoeira de 5 anos, averbada como Reserva Legal); C20 (capoeira de 20 anos, averbada como RL); C30 (capoeira com mais de 30 anos.

Tabela 8. Parâmetros fitossociológicos calculados a partir do levantamento arbóreo nas parcelas contendo agricultura convencional, agrofloresta e capoeira (indices de diversidade, de equabilidade e de dominância).

\begin{tabular}{|c|c|c|c|c|c|c|}
\hline & \multicolumn{4}{|c|}{ Espécies } & \multicolumn{2}{|r|}{ Famílias } \\
\hline & $\mathbf{N}^{0}$ espécies & $\begin{array}{l}\text { Índice de Shannon }\left(\mathrm{H}^{\prime}\right)^{1} \\
\left.\text { (ind. nats }{ }^{-1}\right)\end{array}$ & $\begin{array}{c}\text { Equabilidade } \\
(\mathbf{J})^{2}\end{array}$ & $\begin{array}{c}\text { Índice de } \\
\text { Simpson }(D)^{3}\end{array}$ & $\mathrm{~N}^{0}$ famílias & $\begin{array}{l}\text { Índice de Shannon (H') } \\
\left(\text { famílias nats }^{-1}\right)\end{array}$ \\
\hline Geral & 78 & 3,25 & 0,75 & 0,08 & 31 & 2,63 \\
\hline Agricultura & 2 & 0,06 & 0,09 & 0,98 & 2 & 0,06 \\
\hline $\mathrm{AB}$ & nd & $\mathrm{Nd}$ & nd & nd & nd & nd \\
\hline MA & nd & $\mathrm{Nd}$ & nd & nd & nd & nd \\
\hline PU & 2 & 0,06 & 0,09 & 0,98 & 2 & 0,06 \\
\hline SAF-ME & 48 & 2,39 & 0,62 & 0,23 & 26 & 2,14 \\
\hline SAF 4 & 16 & 1,72 & 0,62 & 0,31 & 13 & 1,64 \\
\hline SAF 8 & 20 & 1,58 & 0,53 & 0,36 & 14 & 1,45 \\
\hline SAF 16 & 32 & 2,73 & 0,79 & 0,11 & 19 & 2,44 \\
\hline Capoeira & 54 & 3,34 & 0,84 & 0,05 & 23 & 2,65 \\
\hline $\mathrm{C} 5$ & 27 & 2,63 & 0,80 & 0,12 & 17 & 2,19 \\
\hline $\mathrm{C} 20$ & 26 & 2,88 & 0,88 & 0,07 & 15 & 2,04 \\
\hline $\mathrm{C} 30$ & 26 & 2,68 & 0,82 & 0,09 & 16 & 2,39 \\
\hline
\end{tabular}

(1) Índice de diversidade de espécies, baseado na abundância proporcional $\left(\mathrm{H}^{\prime}=-\sum p i \ln _{P I}\right)$. (2) Índice de Jaccard, mede a similaridade entre parcelas em termos de composição de espécies; $\mathrm{Sj}=\mathrm{c} /(\mathrm{a}+\mathrm{b}+\mathrm{c})$, no qual a= número de espécies presentes apenas em uma das áreas, $\mathrm{b}=$ número de espécies presentes apenas na outra área analisada, e c= número de espécies presentes em ambas as áreas; (3) Índice de dominância $\left(\mathrm{D}=\sum p i^{2}\right)$; $\mathrm{AB}$ (plantio de abóbora); MA (plantio de maracujá); PU (plantio de pupunha); SAF 4 (jovem); SAF 8 (intermediário); SAF 16 (maduro); C5 (capoeira de 5 anos, averbada como Reserva Legal); C20 (capoeira de 20 anos, averbada como RL); C30 (capoeira com mais de 30 anos). 
No SAF 4, as espécies com maiores valores de VI, além das plantadas com interesse econômico para a produção de frutos, são espécies pioneiras e secundárias iniciais, todas heliófilas (Cecropia glaziovi e Trema micrantha). Nos SAF intermediários (SAF 8), além das espécies arbóreas perenes, observam-se espécies secundárias iniciais a clímax, de caráter esciófilo (Euterpe edulis), enquanto que nos SAF mais maduros (SAF 16), há uma composição diversificada de espécies arbóreas perenes, espécies pioneiras a climácicas, e de caráter heliófilo a esciófilo. Estes resultados mostram que, apesar do direcionamento prático dado pelos produtores locais para a composição desses sistemas agroflorestais, pode-se dizer que há uma aproximação de um processo de sucessão secundária nesses sistemas, com o passar do tempo de plantio, concordando com as teorias apresentadas por Götsch (1997).

Em relação ao número de espécies nas capoeiras, observam-se elevados valores do índice de diversidade de Shannon $\left(\mathrm{H}^{\prime}=3,34\right.$ indivíduos nats $\left.{ }^{-1}\right)$, acompanhado da ausência de dominância (Simpson) e elevada similaridade (Jaccard) entre suas repetições (Tabela 6). Os valores de H' geralmente situam-se entre 1,3 e 3,5, podendo alcançar em torno de 4,5 em ambientes florestais tropicais (Felfili \& Rezende, 2003). Nas áreas com SAF, os valores foram de 1,72 para o SAF 4, 1,58 no SAF 8 e 2,73 no SAF 16 (Tabela 5). Também se observou alta similaridade dessas parcelas ( $\geq 53 \%)$, mesmo que o manejo e a composição dos SAF tenham suas particularidades, para cada produtor agroflorestal.

A baixa biodiversidade é regulada pelo ambiente (Fahrig, 2003), e a conservação da biodiversidade depende da forma como o ambiente é manejado. Lindenmayer et al. (2006) sugerem, entre vários pontos para o manejo da paisagem para fins de conservação, a manutenção da conectividade de habitats, de comunidades e de processos ecológicos, que permitirão a persistência e a recuperação das populações, o fluxo gênico e a reocupação de áreas naturais.

Extensas áreas de floresta nativa em Barra do Turvo foram convertidas em áreas de cultivo, superexploradas em ciclos consecutivos com lavouras de subsistência até o seu declínio produtivo e abandonadas, segundo informações repassadas diretamente pelos produtores rurais e pelos técnicos da Cooperafloresta e Cati. Segundo Giupponi et al. (2006), a reconversão de áreas agrícolas em florestais tende a, com o tempo, promover a sucessão natural, desde que se interrompa o sobremanejo dessas áreas. Assim, a reconversão das áreas agrícolas da Barra do Turvo a capoeiras, em sistema de pousio, permitiu o reaparecimento de espécies nativas da região e, no SAF, este processo vem sendo intensificado, pelo plantio dessas espécies florestais, pelo manejo das podas (que abrem clareiras nos plantios permitindo a regeneração de várias espécies) e pela seleção dos indivíduos por parte dos produtores agroecológicos.

Essas áreas, como descrito anteriormente, faziam parte do mosaico de áreas com exploração agrícola superexplorada pelos agricultores familiares locais, carentes de recursos e de assistência técnica. Independentemente do tempo de pousio, todas as capoeiras foram recuperadas naturalmente, com fontes de propágulos existentes nos fragmentos florestais remanescentes.

Os trabalhos de recuperação ambiental normalmente utilizam algumas dezenas de espécies arbóreas em cada sítio, normalmente aquelas mais abundantes e de fácil obtenção de sementes. A razão para esta prática, segundo Viana \& Pinheiro (1998), é simples: ao aumentar o número de espécies envolvidas nos trabalhos de recuperação ambiental, o custo do empreendimento aumenta de forma exponencial.

Os produtores agroflorestais na Barra do Turvo, no entanto, ao trabalhar em sistema associativo (via Cooperafloresta) e sob a forma de mutirões, conseguem realizar o plantio de diversas espécies (Tabelas 3 e 4) e otimizar o processo de recuperação da biodiversidade de suas áreas. Neste processo de mutirão, as famílias de cada núcleo comunitário (Areia Branca, Cedro-Ribeirão Grande, Terra Seca, Indaiatuba, Salto Grande, Córrego do Franco-Três Canais e BR116) se reúnem semanalmente para planejar as ações comuns no manejo agroflorestal da região. Dessas reuniões nascem as decisões sobre plantios, manejo de podas, aspectos da comercialização, gestão da propriedade rural, entre outros assuntos. No processo de plantio, há troca constante de material (sementes e mudas) entre as famílias, permitindo um fluxo gênico dentro de cada núcleo, além de maior geração de renda para esses produtores, quando comparado à agricultura convencional, tradicional e orgânica (Santos, 2007).

O modelo de SAF utilizado na Barra do Turvo, e seu manejo, mostra-se, desta forma, viável, do ponto de vista ambiental, legal e econômico para a recuperação da RL. 


\section{Diversidade $x$ volume de biomassa florestal produzida nos SAF e nas capoeiras}

Dados levantados diretamente com os produtores, sob a forma de questionário voluntário, mostram a grande diversidade de plantas utilizadas nos SAF em estudo (Tabelas 3 e 4), quer sejam plantadas sob a forma de sementes (na implantação do SAF) ou de mudas (produzidas pelos próprios produtores e distribuídas entre eles por meio de mutirões). Todas as plantas utilizadas mostram-se importantes em algum aspecto, pois possuem potencial de utilização direta (i.e. madeira de lei, para moirão ou para lenha, grãos, frutíferas, etc.), ou indireta (plantas que, independente de outro potencial, podem ser utilizadas como "adubadeiras", tais como as leguminosas arbóreas), cujos critérios para uso no sistema baseiam-se em conceitos próprios desses produtores.

Apesar de compor, historicamente, o principal produto agrícola dos SAF na região, os bananais correspondem no máximo a $2,1 \%$, das espécies cultivadas nesses sistemas. Em todas as áreas analisadas, em torno de $80 \%$ das plantas são arbóreas (entre madeireiras, frutíferas e palmeiras), denotando o esforço desses agricultores em plantar espécies arbóreas em suas propriedades, buscar a diversificação de produtos, sem abandonar as necessidades, em curto prazo, da produção de alimentos via cultivo de hortícolas/olerícolas.

Com o avanço da idade dos SAF, nota-se a diminuição, em até $73,4 \%$, da quantidade total de espécies cultivadas (Tabelas 3 e 4). As espécies de ciclo curto (hortícolas e olerícolas), que representam $10,4 \%$ do total cultivado no SAF 4, representa apenas $6 \%$ no SAF 8 (Tabela 4). Igual comportamento pode ser observado para as espécies frutíferas, que decrescem de $31,6 \%$ para $9 \%$ com o aumento da idade dos SAF. Por outro lado, observa-se um aumento na representatividade de espécies madeiráveis e de palmeiras, visando à produção de produtos de ciclo longo. Outro aspecto interessante é a diminuição na quantidade e porcentagem de espécies de adubação verde ao longo dos anos.

Quando comparamos a área basal total e o volume estimado de biomassa florestal produzida nos SAF multiestrato (Tabela 4), observamos que a baixa produção volumétrica dos $\mathrm{SAF}$, em comparação às áreas de capoeira (Figuras 1 e 2), se dá em função, sobretudo, do manejo silvicultural inadequado por parte daqueles produtores rurais.

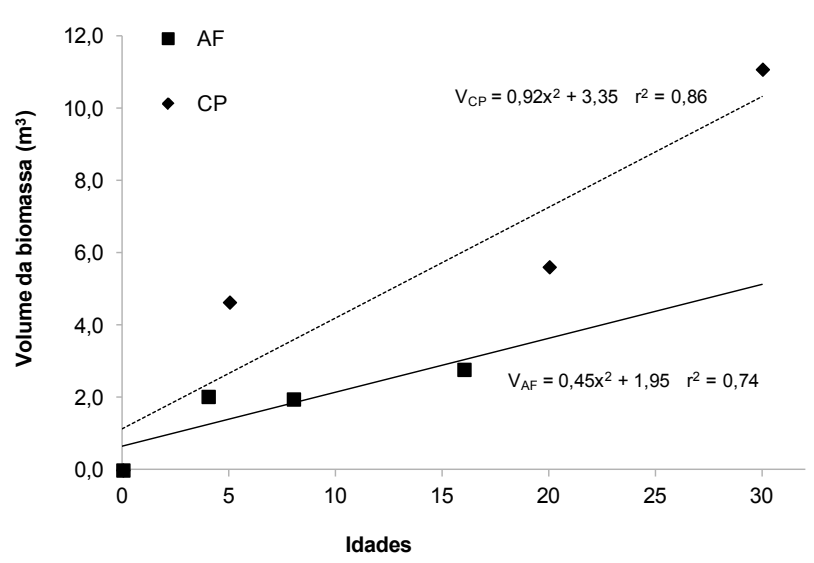

Figura 1. Produção de biomassa $\left(\mathrm{m}^{3}\right)$ nos SAF multiestrata e nas capoeiras no Alto Vale do Ribeira, e estimativa da produção ao longo do tempo. Dados obtidos no inventário fitossociológico em nove parcelas de $25 \mathrm{~m} \mathrm{x} 10 \mathrm{~m}$, dentro de cada um desses sistemas.
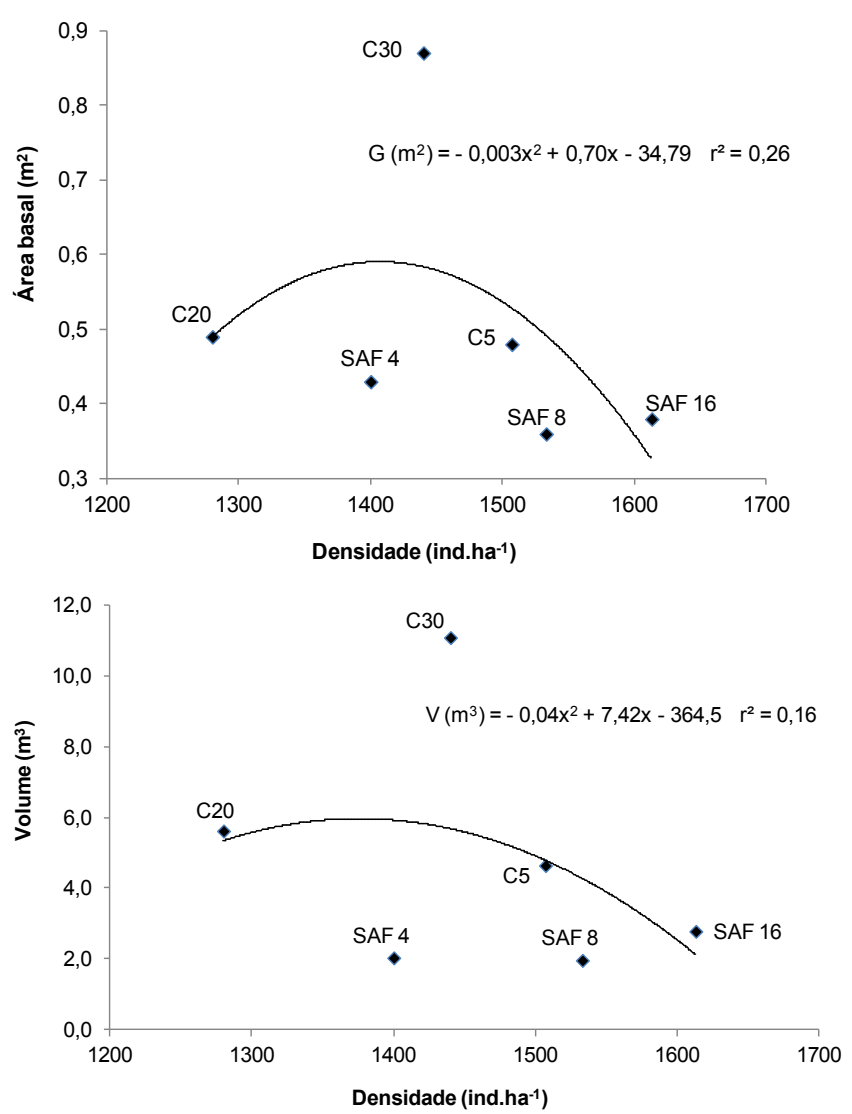

Figura 2. Efeito da alta densidade de plantas nos SAF multiestrato sobre a área basal $\left(\mathrm{m}^{2}\right)$ e o volume $\left(\mathrm{m}^{3}\right)$ de biomassa arbórea produzida;SAF 4 (jovem); SAF 8 (intermediário); SAF 16 (maduro); C5 (capoeira de 5 anos, averbada como Reserva Legal); C20 (capoeira de 20 anos, averbada como RL); C30 (capoeira com mais de 30 anos). 
Historicamente, os produtores agroflorestais associados à Cooperafloresta saíram de uma realidade em que recebiam, via atividade agrícola, menos de um salário mínimo anual para, em quinze anos de atividades, dois salários mínimos mensais. É compreensível, sob a ótica de sobrevivência dessas famílias que esses SAF sejam continuadamente manejados para a produção agrícola, com grande diversidade de alimentos, inclusive estendendo ao máximo os ciclos de produção das culturas agrícolas e/ou inibindo o desenvolvimento das espécies florestais plantadas (Tabela 3).

Um exemplo desse manejo florestal inadequado, quando se pensa na utilização clássica de espécies madeiráveis, é a realização, por parte de alguns produtores, de podas constantes visando à incorporação da biomassa aérea produzida ao solo, sob a forma de adubação verde, como observado para vários exemplares de mogno (Swietenia macrophylla) plantados nessas propriedades agroflorestais, ao invés de conduzir estas mesmas espécies para a produção florestal por meio de técnicas silviculturais apropriadas para produção de madeira para desdobro. Baggio et al. (2009), ao realizarem o inventário do volume de madeira comercial produzida nessas mesmas áreas, concluíram que o atual manejo dado a esses sistemas não favorece a produção de madeira.

Há que se frisar também o aumento da quantidade de espécies de ciclo curto observado no SAF 16 (Tabela 4), também responsável pela menor produção de biomassa vegetal nestes SAF. Esta nova composição de espécies de ciclo curto possivelmente decorre do reaproveitamento de áreas de clareiras formadas pelo corte seletivo de espécies madeiráveis e de frutíferas, ou pela formação de novos SAF a partir de áreas de SAF com maior tempo de manejo, altamente biodiversos, porém estagnados quanto à produção de alimentos, como uma forma de correção de rumo no manejo agroflorestal, aproveitandose das melhorias edáficas obtidas ao longo do tempo desse manejo.

Os SAF multiestrato, além de cumprirem as exigências legais para a execução da RL apresentamse como alternativas viáveis para a produção de alimentos, de produtos madeiráveis e não-madeiráveis dentro da pequena e média propriedade rural e de serviços ambientais (Froufe et al., 2011), necessitando, contudo, experimentação complementar para definir, além do manejo mais correto em todas as suas fases de produção agrícola e florestal, qual é a melhor densidade desses sistemas para promover os ganhos ambientais e econômicos exigidos.

Vale ressaltar que as práticas agroflorestais destes agricultores está se dando em um contexto de constante aprendizado e aperfeiçoamento das práticas que tem levado a significativas mudanças no planejamento e condução dos SAF mais recentes em relação aos aqui estudados. Apesar de conter elementos de sistemas praticados há gerações, uma sistematização de métodos e a incorporação de novas técnicas, notadamente da América Central, vem se intensificando de forma gradativa somente a partir da década de 1990 (Götsch, 1997). Ou seja, trata-se de uma tecnologia agrícola muito recente e que possui um grande potencial de melhorias a serem alcançadas para a sustentabilidade dos SAF multiestrato e para a conservação dos recursos naturais nesses sistemas agroflorestais.

\section{Conclusões}

À luz da legislação vigente, observa-se a aplicabilidade dos SAF multiestrato para a execução da Reserva Legal, pois comporta valores relacionados a número de indivíduos e de espécies nativas in situ, por hectare, superiores ao mínimo preconizado na lei.

A regeneração natural e/ou o sub-bosque dos SAF multiestrato conduzidos no Vale do Ribeira comportam biodiversidade semelhante que as capoeiras naturalmente estabelecidas na região, corroborando o aspecto conservacionista desses sistemas de produção.

Apesar do caráter conservacionista, este sistema ainda carece de melhorias em suas práticas silviculturais no intuito de promover maior aproveitamento das espécies com finalidade madeireira.

\section{Referências}

ANGEL-PÉREZ, A. L. D.; MENDOZA B., M. A. Totonac homegardens and natural resources in Veracruz, Mexico. Agriculture and Human Values, v. 21, n. 4, p. 329-346, 2004. DOI 10.1007/s10460-004-1219-9

BAGGIO, A. J.; SOARES, A. O.; MASCHIO, W. O estrato arbóreo nos sistemas agroflorestais: um estudo de caso e perspectivas do mercado para espécies nativas. Colombo: Embrapa Florestas, 2009. 52 p.

BELTRAME, T. P.; CULLEN JR., L.; RODELLO, C. M.; LIMA, J. F.; BORGES, H. Sistemas agroflorestais na recuperação de áreas de Reserva Legal: um estudo de caso do Pontal do Paranapanema, São Paulo. Revista Brasileira de Agroecologia, v. 1, n. 1, p. 189193, nov. 2006.

Pesq. flor. bras., Colombo, v. 31, n. 67, p. 203-225, jul./set. 2011 
BENJAMIN, T. J.; MONTAÑEZ, P. I.; JIMÉNEZ, J. J. M.; GILLESPIE, A. R. Carbon, water and nutrient flux in Maya homegardens in the Yucatán peninsula of Mexico. Agroforestry Systems, v. 53, n. 2, p. 103-111, 2001.

\section{BIODIVERSITAS-INTERNATIONAL UNION FOR} CONSERVATION OF NATURE. Revisão da lista da flora brasileira ameaçada de extinção. Belo Horizonte, [2005]. <http:// www.biodiversitas.org.br/floraBr/grupo3fim.asp > . Acesso em: 30 abr. 2010.

BRASIL. Lei $\mathbf{n}^{\circ} \mathbf{4 . 7 7 1}$ de 15 de setembro de $\mathbf{1 9 6 5}$. Institui o Novo Código Florestal . Disponível em: $<$ http://www.planalto.gov. br/ccivil 03/Leis/L4771.htm>. Acesso em: 21 mar. 2010. Texto atualizado publicado originalmente no Diário Oficial da República Federativa do Brasil, Brasília, DF, 16 set. 1965.

BRASIL. Lei no ${ }^{0} .171$ de 17 de janeiro de 1991. Dispõe sobre a política agrícola. Disponível em: $<$ http://www.planalto.gov. br/ccivil_03/Leis/L8171.htm>. Acesso em: 22 mar. 2010. Texto atualizado publicado originalmente no Diário Oficial da República Federativa do Brasil, Brasília, DF, 18 jan. 1991.

BRASIL. Medida provisória $\mathbf{n}^{\mathbf{0}} \mathbf{2 . 1 6 6 - 6 7}$ de 24 de agosto de 2001. Altera os arts. 1o, 4o, 14, 16 e 44, e acresce dispositivos à Lei $\mathrm{n}^{\circ} 4.771$, de 15 de setembro de 1965 , que institui o Código Florestal, bem como altera o art. 10 da Lei $n^{\circ} 9.393$, de 19 de dezembro de 1996, que dispõe sobre o Imposto sobre a Propriedade Territorial Rural - ITR, e dá outras providências. Disponível em: <http://www.receita.fazenda.gov.br/legislacao/ MPs/mp2166-67.htm>. Acesso em: 21 mar. 2010. Texto atualizado publicado originalmente no Diário Oficial da República Federativa do Brasil, Brasília, DF, 25 ago. 2001.

BRASIL. Instrução Normativa ${ }^{\circ} 5$ de 8 de setembro de 2009. Dispõe sobre procedimentos metodológicos para restauração e recuperação das Áreas de Preservação Permanentes e da Reserva Legal. Diário Oficial [da] República Federativa do Brasil, Brasília, DF, 9 set. 2009. Disponível em: <http://media0. agrofloresta.net/static/publicacoes/MMA-9_setembro_2009instrucao_normativa_3_4_5.pdf $>$. Acesso em: 21 mar. 2010

BUDOWSKI, G. Distribution of tropical american rain forest species in the light of sucessional processes. Turrialba, v. 15, n. 1, p. $40-42,1965$.

CAJA-GIRON, Y. S.; SINCLAIR, F. L. Characterization of multistrata silvopastoral systems on seasonally dry pastures in the Caribbean Region of Colombia. Agroforestry Systems, v. 53, p. 215-225, 2001.

CANALEZ; G. G.; CÔRTE, A. P. D.; SANQUETTA, C. R.; BERNI, D. M. Dinâmica da Araucaria angustifolia (Berg.) O. Ktze. e Ilex paraguariensis St. Hill. em duas florestas de araucária no Estado do Paraná, Brasil. Ambiência, Guarapuava, v. 2, n. 1, p. 9-22, jan./jun. 2006.

CARDOSO-LEITE, E.; COVRE, J. B.; OMETTO, R. G.; CAVALCANTI, D. C.; PAGANI, M. I. Fitossociologia e caracterização sucessional de um fragmento de mata ciliar, em Rio Claro/SP, como subsídio à recuperação da área. Revista do Instituto Florestal, São Paulo, v. 16, n. 1, p. 31-41, jun. 2004.
CARPANEZZI, A. A.; CARPANEZZI, O. T. B. Espécies nativas recomendadas para a recuperação ambiental no Estado do Paraná, em solos não degradados. Colombo: Embrapa Florestas, 2006. 52 p. (Embrapa Florestas. Documentos, 136).

DAILY, G. C.; EHRLICH, P. R.; SANCHEZ-AZOFEITA, G. A. Countryside biogeography: use of human-dominated habitats by the avifauna of southern Costa Rica. Ecological Applications, v. 11, p. 1-13, 2001.

FAHRIG, L. Effects of habitat fragmentation on biodiversity. Annual Review of Ecology, Evolution and Systematics, v. 34, p. 487-515, 2003.

FELFILI, J. M.; REZENDE, R. P. Conceitos e métodos em fitossociologia. Brasília, DF: UNB, Departamento de Engenharia Florestal, 2003. 68 p. (UNB. Comunicações técnicas florestais, v. 5, n. 1).

FROUFE, L. C. M.; RACHWAL, M. F. G.; SEOANE, C. E. S. Potencial de sistemas agroflorestais multiestrata para sequestro de carbono em áreas de ocorrência de Floresta Atlântica. Pesquisa

Florestal Brasileira, Colombo, v. 31, n. 66, p. 143-154, abr./jun. 2011. DOI 10.4336/2011.pfb.31.66.143

GIUPPONI, C.; RAMANZIN, M.; STRARARO, E.; FUSER, S. Climate and land-use changes, biodiversity and agri-environmental measures in the Belluno province, Italy. Environmental Science and Policy, v. 9, p. 163-173, 2006.

GÖTSCH, E. Homem e natureza: cultura na agricultura. 2. ed. Recife: Centro de Desenvolvimento Agroecológico Sabiá, 1997. 12 p.

GRANADOS, L. A. C. Viabilidad financiera de sistemas agrosilvopastoriles multiestrata y agroflorestales, en fincas ganaderas convencionales del Departamento de Santander, Colombia. 2005. 146 f. Tesis (Magíster Scientiae) -Programa de Educación para el Desarrollo y la Conservación del Centro Agronómico Tropical de Investigación y Enseñanza,Turrialba, Costa Rica.

HOLGUÍN, V. A.; IBRAHIM, M.; MORA-DELGADO, J. El aprendizaje participativo como base de un cambio positivo del uso del suelo en fincas ganaderas de Costa Rica. Livestock Research for Rural Development, 19, artigo 53, 2007. Disponível em: $<$ http://www.lrrd.org/lrrd19/4/holg19053.htm>. Acesso em: 28 jun. 2007.

ISAAC, M. E.; TIMMER, V. R.; QUASHIE-SAM, S. J. Shade tree effects in an 8-year-old cocoa agroforestry system: biomass and nutrient diagnosis of Theobroma cacao by vector analysis. Nutrient Cycling in Agroecosystems, v. 78, p. 155-165, 2007.

LEAL, F. H. O mecanismo de desenvolvimento limpo como incentivo à recomposição de Áreas de Preservação Permanente e Reserva Legal. In: CONGRESSO INTERNACIONAL DE DIREITO AMBIENTAL, 11.,2007, São Paulo. Meio ambiente e acesso à justiça: flora, reserva legal e APP, [São Paulo]: Instituto O Direito por um Planeta Verde, [2007]. v. 1. p. 287-295.

LEHMANN, J.; GÜNTHER, D.; MOTA, M. S. da; ALMEIDA, M. P. de; ZECH, W.; KAISER, K. Inorganic and organic soil phosphorus and súlfur pools in an Amazonian multistrata agroforestry system. Agroforestry Systems, v. 53, p. 113-124, 2001. 
LINDENMAYER, D. B.; FRANKLIN, J. F.; FISCHER, J. General management principles and a checklist of strategies to guide forest biodiversity conservation. Biological Conservation, v. 131, p. 433-445, 2006. DOI10.1016/j.biocon.2006.02.019

OLIVEIRA-FILHO, A. T. Composição florística e estrutura comunitária da Floresta de Galeria do Córrego da Paciência, Cuiabá (MT). Acta Botanica Brasílica, v. 3, n. 1, p. 91-112. 1989.

PARANÁ. Instituto Ambiental do Paraná. Portaria IAP 157, de 13 de outubro de 2005. Normatiza o uso de espécies arbóreas exóticas na Reserva Legal. Disponível em: <http://celepar7.pr.gov. $\mathrm{br} /$ sia/atosnormativos/form_cons_ato1.asp?Codigo $=1190>$. Acesso em: 21 mar. 2005.

PARANÁ. Resolução SEMA nº 13/2010, de 24 de março de 2010. Institui modelos, procedimentos e conceitos aplicáveis na recuperação de Reserva Legal para o agricultor familiar e empreendedor familiar rural. Disponível em: $<$ http://www.iap.pr.gov.br/arquivos/ File/Legislacao_ambiental/Legislacao_estadual/RESOLUCOES/ RESOLUCAO_SEMA_13_2010_RECUPERACAO_RESERVA LEGAL.pdf $>$. Acesso em: 21 mar. 2010.

PIELOU, E. C. Ecological diversity. New York: WileyInterscience, 1975.

RIBEIRO, M. C.; METZGER, J. P.; MARTENSEN, A. C.; PONZONI, F. J.; HIROTA, M. M. The Brazilian Atlantic Forest: how much is left, and how is the remaining forest distributed? implications for conservation. Biological Conservation, v. 142, n. 6, p. 1141-1153, June 2009.

ROUSSELET-GADENNE, A. Adoption d'innovations agroforestières à Barra do Turvo (São Paulo, Brésil). Cahiers d'Agriculture, Paris, v. 13, n. 5, p. 391-402, 2004.

SANTOS, A. C. dos. As contradições da economia de mercado: um olhar sobre a renda da agricultura agroecológica. Disponível em: <http://media0.agrofloresta.net/static/artigos/Renda_da Agricultura_Familiar_Alvori.pdf $>$. Acesso em: 21 mar. 2010.

SANTOS, H. G. dos; JACOMINE, P. K. T.; ANJOS, L. H. C. dos; OLIVEIRA, V. A. de; OLIVEIRA, J. B. de; COELHO, M. R.; LUBRERAS, J. F.; CUNHA, T. J. F. da (Eds.). Sistema Brasileiro de classificação de solos. 2. ed. Brasília, DF: Embrapa Informação Tecnológica; Rio de Janeiro: Embrapa Solos, 2006, $306 \mathrm{p}$.

SANTOS, M. J. C.; RODRIGUEZ, L. C. E.; WANDELI, E. V. Avaliação econômica de quatro modelos agroflorestais em áreas degradadas por pastagens na Amazônia Ocidental. Scientia Florestalis, Piracicaba, SP, v. 62, p. 48-61, 2002.
SÃO PAULO (Estado). Decreto $\mathbf{n}^{\circ} \mathbf{5 0 . 8 8 9}$, de 16 de junho de 2006. Dispõe sobre a manutenção, recomposição, condução da regeneração natural e compensação da área de Reserva Legal de imóveis rurais no Estado de São Paulo. Disponível em: $<$ http:// www.al.sp.gov.br/repositorio/legislacao/decreto/2006/decreto $\% 20$ n. $50.889, \% 20 \mathrm{de} \% 2016.06 .2006 . \mathrm{htm}>$. Acesso em: 21 mar. 2010

SCHROTH, G.; D'ANGELO, S. A.; TEIXEIRA, W. G.; HAAG, D.; LIEBEREI, R. Conversion of secondary forest into agroforestry and monoculture plantations in Amazonia: consequences for biomass, litter and soil carbon stocks after 7 years. Forest Ecology and Management, v. 163, p. 131-150, 2002.

SHANNON, C. E.; WEAVER, W. The mathematical theory of comunication. Urbana: Universty of Illinois Press, 1949.

SHEPHERD, G. J. FITOPAC 1: manual de usuário. Campinas: Departamento de Botânica, UNICAMP, 1995.93 p.

SILVEIRA, N. D. Sostenibilidad socioeconómica y ecológica de sistemas agroflorestales de café (Coffea arabica) en la microcuenca del Río Sesesmiles, Copán, Honduras. 2005. 154 f. Tese (Magister Scientiae en Agroforestería Tropical) Centro Agronómico Tropical de Investigación y Enseñanza,Turrialba, Costa Rica.

SOCIEDADE DE PESQUISA EM VIDA SELVAGEM. Manual para recuperação da reserva florestal legal. Curitiba: FNMA, 1996. $84 \mathrm{p}$.

STAVER, C.; GUHARAY, F.; MONTEROSSO, D.; MUSCHLER, R. G. Designing pest-supressive multiestrata perennial crop systems: shade-grown coffee in Central America. Agroforestry Systems, v. 53, p. 151-170, 2001.

SUYANTO, S.; PERMANA, R. P.; KHUSUSIYAH, N.; JOSHI, L. Land tenure, agroforestry adoption, and reduction of fire hazard in a forest zone: a case study from Lampung, Sumatra, Indonesia. Agroforestry Systems, v. 65, p. 1-11, 2005.

VELOSO, H. P.; GÓES-FILHO, L. Fitogeografia brasileira: classificação fisionômico-ecológica da vegetação neotropical. Salvador, BA: [s.n.], 1982. 85 p. Projeto RADAMBRASIL.

VIANA, V. M.; PINHEIRO, L. A. F. V. Conservação da biodiversidade em fragmentos florestais. Série Técnica IPEF, Piracicaba, SP, v. 12, n. 32, p. 25-42, dez. 1998 
